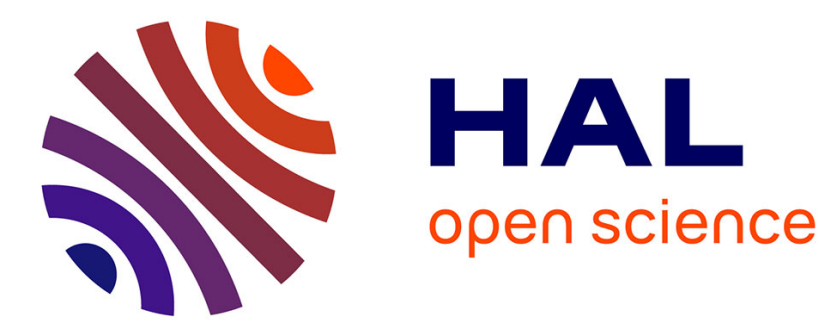

\title{
Un diagnostic au cœur de la ville médiévale d'Orchies : découverte d'un ensemble statuaire remarquable
}

Marion Audoly, Laetitia Barragué-Zouita, Ludovic Debs, Vaiana Vincent

\section{To cite this version:}

Marion Audoly, Laetitia Barragué-Zouita, Ludovic Debs, Vaiana Vincent. Un diagnostic au cœur de la ville médiévale d'Orchies : découverte d'un ensemble statuaire remarquable. Revue du Nord, 2015, 413 (5), pp.281-303. 10.3917/rdn.413.0281 . hal-02139187

\section{HAL Id: hal-02139187 https://hal-inrap.archives-ouvertes.fr/hal-02139187}

Submitted on 3 Jun 2019

HAL is a multi-disciplinary open access archive for the deposit and dissemination of scientific research documents, whether they are published or not. The documents may come from teaching and research institutions in France or abroad, or from public or private research centers.
L'archive ouverte pluridisciplinaire HAL, est destinée au dépôt et à la diffusion de documents scientifiques de niveau recherche, publiés ou non, émanant des établissements d'enseignement et de recherche français ou étrangers, des laboratoires publics ou privés. 


\title{
UN DIAGNOSTIC AU CEEUR DE LA VILLE MÉDIÉVALE D’ORCHIES : DÉCOUVERTE D’UN ENSEMBLE STATUAIRE REMARQUABLE
} Marion Audoly, Laetitia Barragué-Zouita, Ludovic Debs et Vaiana Vincent

\author{
Association Revue du Nord | « Revue du Nord »
}

2015/5 n 413 | pages 281 à 303

ISSN 0035-2624

Article disponible en ligne à l'adresse :

https://www.cairn.info/revue-du-nord-2015-5-page-281.htm

Distribution électronique Cairn.info pour Association Revue du Nord.

(C) Association Revue du Nord. Tous droits réservés pour tous pays.

La reproduction ou représentation de cet article, notamment par photocopie, n'est autorisée que dans les limites des conditions générales d'utilisation du site ou, le cas échéant, des conditions générales de la licence souscrite par votre établissement. Toute autre reproduction ou représentation, en tout ou partie, sous quelque forme et de quelque manière que ce soit, est interdite sauf accord préalable et écrit de l'éditeur, en dehors des cas prévus par la législation en vigueur en France. Il est précisé que son stockage dans une base de données est également interdit. 


\section{Un diagnostic au cour de la ville médiévale d'Orchies : découverte d'un ensemble statuaire remarquable}

\section{INTRODUCTION (M. Audoly)}

Le centre-ville d'Orchies (Nord) occupe encore aujourd'hui l'emplacement de la ville médiévale, dont l'existence est attestée depuis le $\mathrm{XII}^{\mathrm{e}} \mathrm{s}$. La « villa de Orchies » apparaît en effet dans un discours de 1188 de Philippe, comte de Flandres, rapporté par Ferry de Locre en $1616^{1}$.

Si la topographie de la ville médiévale est bien connue, car documentée par plusieurs plans, peu de vestiges de ce passé sont encore aujourd'hui conservés et ont pu être étudiés. Ainsi, le plan du cartographe néerlandais Jacob van Deventer montre, en 1570 , une ville fortifiée, ceinte d'un rempart comprenant une dizaine de tours et cinq portes. L'enceinte quadrangulaire est complétée par un large fossé. D'après E. Draux ${ }^{2}$, la première enceinte de la ville pourrait remonter au XIIII ${ }^{\mathrm{e}} \mathrm{s}$., date à laquelle la ville achète les terrains où sont construits les remparts et les fossés. Elle connaît des réfections importantes, autorisées par Charles Quint en 1575, comprenant notamment l'édification de tours de guet aux portes de la ville. Quelques vestiges encore en élévation subsistent de cette enceinte. La Tour à Diables, classée Monument Historique en 1922, est située entre la rue de Fleurus et la rue Jules Ferry. Au sud-est de la Tour à Diables, rue Poutrain, deux tours plus petites attribuées $\mathrm{au} \mathrm{XVI}^{\mathrm{e}} \mathrm{s}$. matérialiseraient la Porte des Capucins.
Les opérations d'archéologie préventive, menées à l'occasion des projets d'aménagements, ont donc pour but d'appréhender ce passé médiéval, en permettant notamment de mieux localiser et de dater les éléments figurés ou mentionnés par les sources historiques. Un sondage entre la rue de la Poterne et la rue Gaston Leroy (ancienne rue des Casernes) ${ }^{3}$, dans la zone présumée des remparts médiévaux, avait révélé la présence d'un puits lié aux casernes du XVIII ${ }^{\mathrm{e}} \mathrm{s}$. et d'un mur maçonné en demi-cercle auquel était accolé le massif d'un escalier en colimaçon. Cet élément semble confirmer la présence à cet emplacement de l'une des portes de la ville, visible sur les plans anciens. Un diagnostic, mené rue Jules Ferry en 2003, a permis d'observer un mur de courtine ${ }^{4}$. Situé à l'ouest de la rue Ferry, son tracé, d'orientation nordest/sud-ouest, est parallèle à la rue. Le mur, entièrement fait de briques, mesure $1 \mathrm{~m}$ d'épaisseur. Un décrochement de $0,4 \mathrm{~m}$ de large par un mètre de long pourrait indiquer l'emplacement d'une poterne. Une troisième opération menée en $2015^{5}$, rue Delommez, a confirmé que la rue actuelle a conservé le tracé de l'enceinte, bien que décalée de vingt-cinq mètres plus au sud. Enfin, deux diagnostics ont été réalisés dans la ville intra-muros. Le premier, rue Wattrelot n'a pas atteint les niveaux archéologiques sous les remblais contemporains ${ }^{6}$.
*. - Marion AUdoly, conservateur du patrimoine, DRAC-SRA NordPas-de-Calais Picardie, 3 rue du Lombard, 59049 Lille Cedex ; Laetitia BARRAGUÉ-ZoutTA, conservateur du patrimoine, Palais des Beaux-Arts, 18 bis rue de Valmy, 59000 Lille; Ludovic Debs, Inrap, Vaiana VinCENT, Inrap. Nous remercions Thomas Nicq, HALMA 8164, pour le traitement numérique.

\footnotetext{
1. - LOCRE 1616, p. 128.

2. - DrauX 1980.

3. - RouMÉGOUX 1992.

4. - HosDEZ 2003

5. - VINCENT 2015

6. - Hosdez 2012.
} 
Le projet de construction d'un immeuble, rue Letellier, sur l'un des rares terrains encore accessibles et non bâtis sur les cadastres anciens, constituait donc une opportunité rare d'appréhender la topographie et l'évolution de la ville médiévale intra-muros. Le Service régional de l'Archéologie a donc décidé la réalisation d'un diagnostic avant la mise en œuvre du projet. L'opération menée par L. Debs ${ }^{7}$, dont les résultats sont présentés ici, a conduit à la mise au jour d'une occupation des $\mathrm{XIII}^{\mathrm{e}}$-XIV ${ }^{\mathrm{e}} \mathrm{s}$. et à la découverte de quatre statues: deux statues de saintes du début du $\mathrm{XVI}^{\mathrm{e}}$ s. d'une qualité remarquable (sainte MarieMadeleine et sainte Agnès), et deux statues de moines, plus petites, de la seconde moitié du $\mathrm{XvI}^{\mathrm{e}} \mathrm{s}$.

Cette découverte rare constitue un témoignage exceptionnel de l'art médiéval régional. À ce titre, les quatre statues ont d'ores et déjà rejoint les collections du Palais des Beaux-Arts de Lille, pour y être prochainement présentées au public.

\section{LE DIAGNOSTIC ARCHÉOLOGIQUE (L. Debs)}

Les informations présentées ici sont celles d'un diagnostic ${ }^{8}$, opération d'ampleur nécessairement limitée dont le but est de déterminer la présence de vestiges archéologiques à l'occasion d'un projet de construction et si nécessaire de collecter les informations permettant d'y conduire une fouille archéologique. Les données sont donc très partielles. Elles sont issues de cinq tranchées représentant $20 \%$ de la superficie du terrain. Ce diagnostic s'est rapidement heurté à un obstacle naturel. Â la fin du mois de mars, après un hiver assez pluvieux, la nappe phréatique s'est révélée très haute. Selon les secteurs du chantier, seuls 10 à $30 \mathrm{~cm}$ de la stratigraphie médiévale ont pu être observés dans des conditions correctes, le reste, soit 70 à $90 \mathrm{~cm}$, étant complètement noyé. Il est donc apparu rapidement inutile de multiplier les excavations en profondeur qui n'avaient pour effet que de détruire les vestiges sans apporter d'informations supplémentaires.

\subsection{Un contexte encore mal connu}

Il s'agit du premier, et jusqu'à aujourd'hui du seul diagnostic réalisé dans Orchies intra-muros ayant atteint les couches d'occupation médiévales. On ne connaît pas l'aspect de la ville avant la construction de l'enceinte en 1429. La motte féodale et l'église sont les seuls éléments antérieurs qui peuvent être situés avec une quasi-certitude grâce aux plans.

\section{7. - DeBs 2013.}

8. - L'équipe de diagnostic était composée de Ludovic Debs et Vaiana Vincent. Frédéric Auduit a réalisé les relevés topographiques. Après la découverte de la fosse 1010, Corinne Gardais a contribué à la sécurisa-

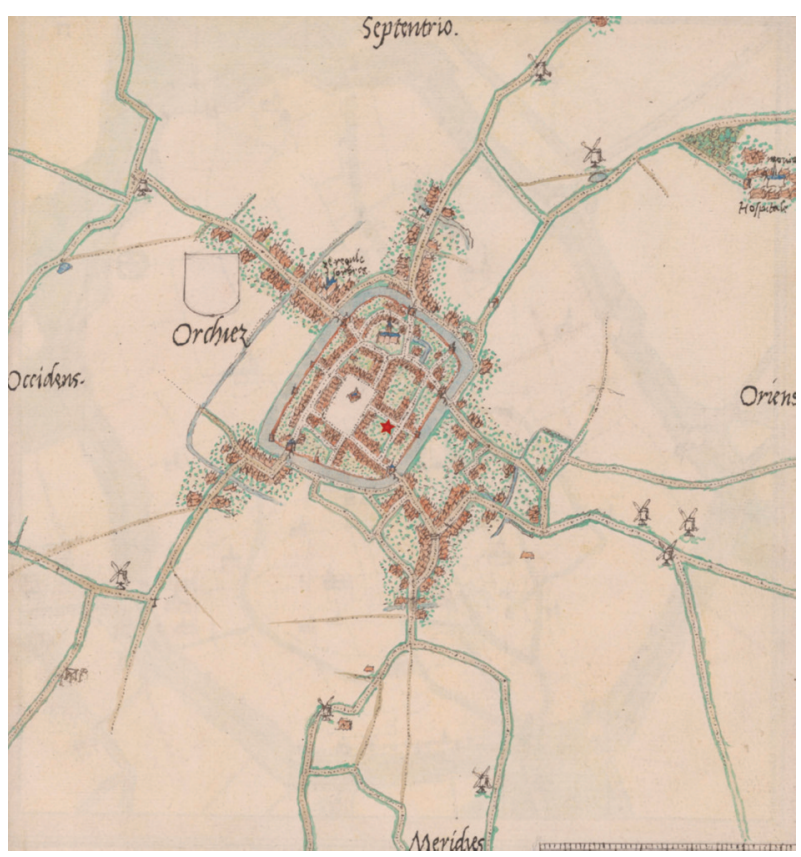

FIG. 1. - Plan d'Orchies vers 1545 par Jacob de Deventer. Numérisation BN Espagne.

Le plan le plus ancien d'Orchies est celui de Jacques de Deventer daté de 1570 (fig. 1). Le fossé extérieur qui apparaît continu sur le cadastre napoléonien n'y est représenté qu'à l'ouest et au sud comme s'il n'était pas encore terminé. Des faubourgs se développent hors les murs au débouché de chaque porte de la ville. Au nord-est, le couvent des Sœurs Grises, fondé en 1538 est proche de la ville, il est identifiable par son église et semble noyé au milieu des maisons. Il occupe l'emplacement d'un ancien béguinage. L'hôpital Notre-Dame de Theomolin est au nord et semble assez isolé. Cet hôpital est installé dans la seconde moitié du XIII ${ }^{\mathrm{e}}$ s. en lieu et place d'un monastère cistercien fondé en 1234 par Jeanne de Flandre et transféré peu après à Flines. On accède à la ville close par cinq portes fortifiées. L'enceinte urbaine est renforcée par au moins six tours. La ville s'articule autour de la grand-place rectangulaire sur laquelle on distingue un bâtiment public, sans doute l'hôtel de ville qui apparaît désaxé par rapport à la place. Il est possible que la place ait été créée au moment de la construction de l'enceinte en 1429 et que l'hôtel de ville soit antérieur et ait été orienté sur un parcellaire

tion des statues et assuré leur réception au centre de recherches de $\mathrm{La}$ Pilaterie, Benoît Duriez en a géré les aspects techniques et Dominique Bossut a réalisé une couverture photographique de l'opération. 
plus ancien. Le réseau de rues est presque identique à celui du XIX ${ }^{\mathrm{e}} \mathrm{s}$.; de nombreux espaces non bâtis sont représentés. Au nord de la ville, l'église est entourée d'un espace vide, vraisemblablement le cimetière. À l'est de l'église, le château est bien visible; il est bordé d'un fossé sur les côtés nord et est, les rues sur les deux autres côtés sont sans doute à l'emplacement du reste du fossé, comblé au moment où le château perd son rôle défensif. Au sud-ouest, la parcelle dans laquelle le couvent des Capucins sera construit sans doute au début du XVII ${ }^{\mathrm{e}} \mathrm{s}$. paraît bien vide. On y distingue seulement un bâtiment sur le côté ouest de l'îlot. Il en va de même de l'îlot sur lequel se trouve la parcelle diagnostiquée qui n'est bâtie que sur deux côtés.

Tant d'espaces vides reflètent sans doute le déclin économique de la ville qui a perdu sa position de grande ville drapante. Elle est, des trois châtellenies de Flandre gallicante, celle qui supporte le moins bien la crise du textile, Douai réussissant à limiter les dégâts et Lille prenant la première place. Orchies n'a, il est vrai, jamais atteint leur importance économique et n'est le siège d'aucune institution comtale.

Dans les albums de Croÿ, dans les premières années du XVII ${ }^{\mathrm{e}}$ s., Orchies est représentée du sudouest. Hors les murs, on distingue à droite la chapelle des Sœurs Grises dans le faubourg de Lille, et plus loin l'hôpital de Theomolin. Orchies apparaît ceinte d'un large fossé en eau et d'un mur muni de tours assez conforme au plan de Deventer. L'église paraît surdimensionnée et écrase la ville de sa hauteur. On distingue également un bâtiment de quelque importance à droite qui pourrait être la maison du Roi, et un autre à gauche semble à l'emplacement de la maison de ville.

Ambroise le Camp en 1639 représente la ville selon une orientation plus difficile à déterminer (fig. 2). Le dessin ne montre pas les faubourgs. Deux ponts permettent de franchir le fossé. L'enceinte avec ses portes et ses tours est figurée. À l'intérieur, l'agglomération semble assez dense; on reconnaît l'église; une tour à droite pourrait être le beffroi (construit en 1609). Le clocher en arrière-plan est vraisemblablement celui du couvent des capucins, ce qui voudrait dire que la vue est prise du nord.

Le cadastre napoléonien daté de 1817 montre que la ville est encore très proche de celle de 1570 (fig. 3). Les deux institutions religieuses situées hors les murs avant la Révolution, l'hôpital Notre-Dame de Théomolin et le couvent des Sœurs Grises, ne sont plus visibles sur le plan. Tout au plus, l'hôpital apparaît comme toponyme aux limites est de la commune. Le fossé extérieur au tracé irrégulier englobe la plus

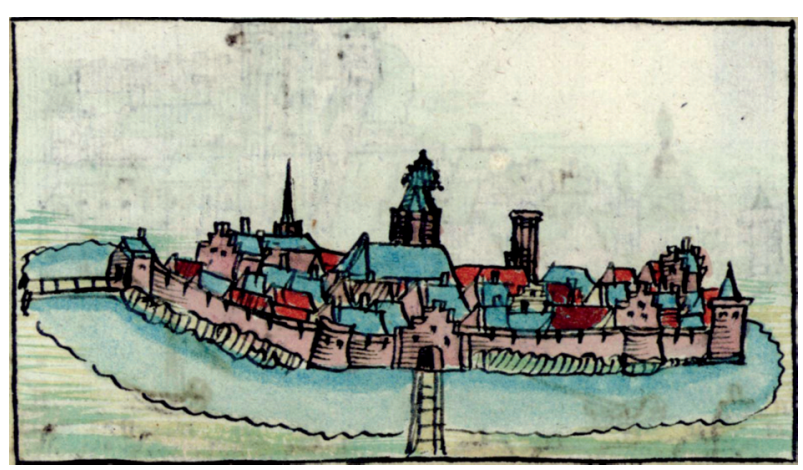

FIG. 2. - Orchies en 1639 par Ambroise Le Camp. Numérisation BM Lille.

grande partie des quatre faubourgs. L'enceinte quadrangulaire ne semble pas avoir subi de bouleversements destinés à l'adapter aux besoins militaires à l'époque moderne, la ville n'ayant visiblement plus d'importance stratégique après le Moyen Âge. Cette enceinte est ruinée depuis la fin du $\mathrm{XVII}^{\mathrm{e}} \mathrm{s}$.

À l'intérieur de cette enceinte, le réseau de rues est proche de celui de la fin du Moyen Âge, seules de petites voies menant à la fortification ont disparu au profit de parcelles bâties. L'église est au même emplacement et l'enclos du cimetière bien visible. Le château a disparu, de même que ses fossés nord et est. En revanche, un fossé apparaît au sud, qui est absent du plan de 1570. Au sud-ouest, le couvent des Capucins se trouve le long de la rue du même nom. Une grande partie du côté sud-est de la ville est occupée par des installations militaires. La Grand'Place, place dauphine à l'époque, est un vaste espace à l'intérieur duquel se trouvent un puits public et l'hôtel de ville, toujours de biais par rapport aux rangs de maisons qui cernent la place.

La parcelle concernée par le diagnostic apparaît au $\mathrm{XIX}^{\mathrm{e}} \mathrm{s}$. à l'angle de la rue de la Vignette qui mène à la grand-place, et de la rue des Casernes. Elle est, semble-t-il, à cheval sur deux parcelles à cette époque, la $\mathrm{n}^{\circ} 485$ qui occupe l'angle et une petite partie de l'extrémité de la ${ }^{\circ} 79$. Dans la propriété 485 , un bâtiment donne sur la rue des Casernes, un autre est en fond de jardin. L'angle des deux rues ne semble pas construit.

\subsection{Une occupation médiévale}

Partout où il a pu être observé, le terrain naturel est constitué de limon jaune culminant vers $1,2 \mathrm{~m}$ sous le sol actuel. Il est surmonté d'une couche d'une tren- 


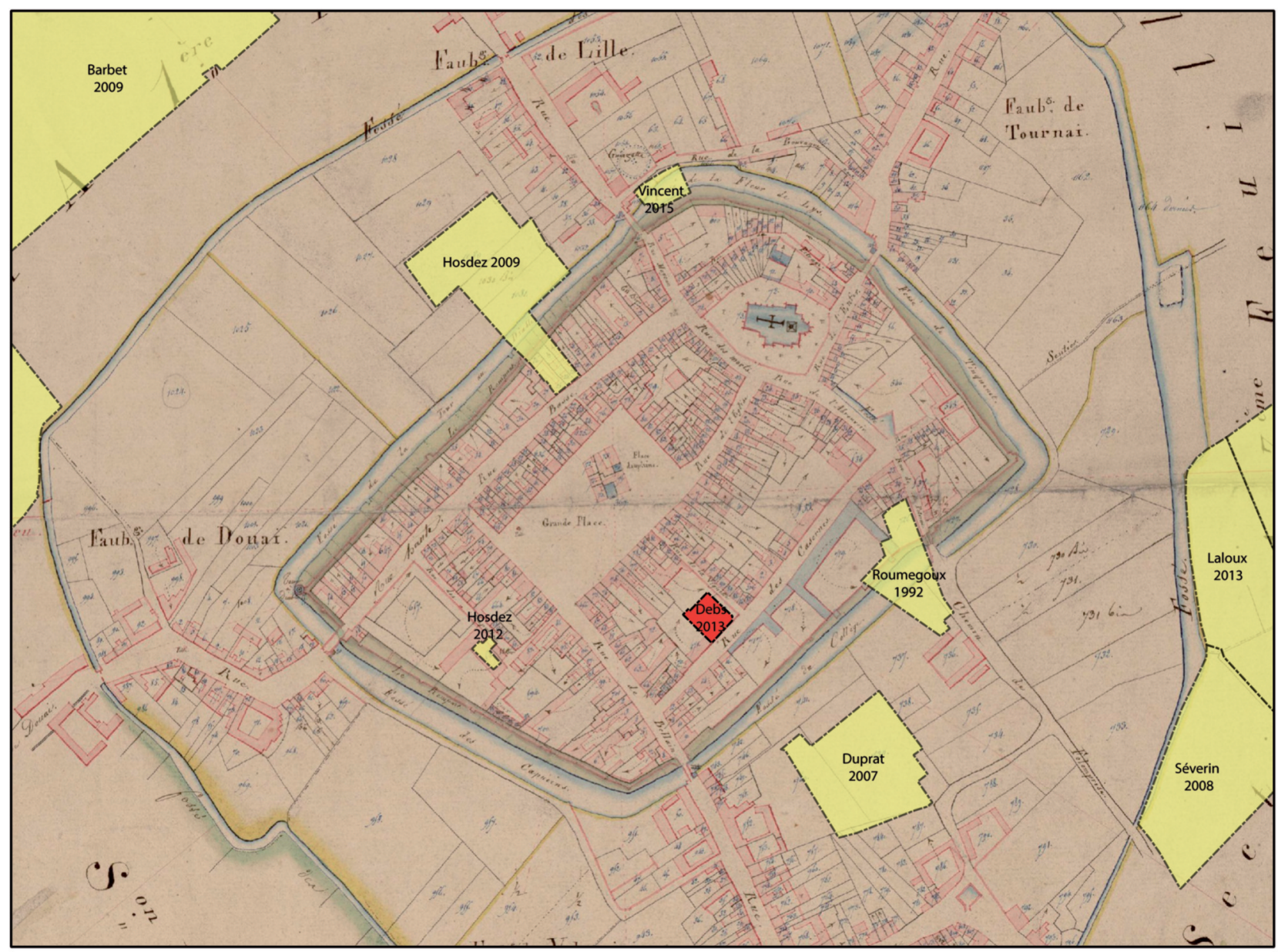

FIG. 3. - Extrait du cadastre d'Orchies de 1817 et emprise des opérations archéologiques.

AD Nord, P31. 163, numérisation ADN, DAO V. Vincent.

taine de centimètres de terre végétale qui semble antérieure à toute urbanisation. Les deux tessons découverts dans cette couche sont datés du Bas Moyen Âge.

Le site médiéval tel qu'il a pu être découvert lors du diagnostic se présente assez classiquement sous la forme de bâtiments en front de rues et de jardins percés de fosses en arrière des parcelles. Dans la tranchée 4 , on note une nette différence entre deux secteurs, dès le niveau d'apparition des sols médiévaux. On trouve du côté sud, un sol jaune clair et au nord, un sol plus orangé. En coupe, la succession de sols apparaît nettement plus épaisse au sud qu'au nord. Il paraît donc évident qu'une cloison devait séparer ces sols, cloison qui n'est plus visible: un mur de briques moderne profondément fondé se trouve à cet emplacement. Ce mur également repéré dans la tranchée 1 correspond à une limite parcellaire visible sur le cadastre napoléonien. Il divise le site entre deux propriétés existant vraisemblablement déjà au Moyen Âge (fig. 4).
La première parcelle à l'angle des deux rues est un rectangle de $12 \mathrm{~m}$ de large pour $23 \mathrm{~m}$ de long en 1817 , largeur réduite de 3,5 m lors d'un élargissement de la rue au XIX ${ }^{\mathrm{e}}$ ou $\mathrm{XX}^{\mathrm{e}} \mathrm{s}$. Des sols de terre battue correspondant à des bâtiments ont été trouvés dans l'ensemble de la parcelle. Dans la tranchée 1, ces sols apparaissent $25 \mathrm{~cm}$ plus bas que dans la tranchée 4 et seuls les dix premiers centimètres sont visibles; le reste est inondé.

Le sondage profond pratiqué à l'angle des tranchées 4 et 5 , montre que les sols de terre battue reposent directement sur la couche de terre végétale. On y distingue au moins deux phases successives. Une troisième, la dernière, est lacunaire, soit qu'il s'agisse juste de recharges ou que le sol ait été arasé ultérieurement. Il en va de même pour une couche discontinue de cailloutis calcaire qui pourrait correspondre à un sol presque complètement érodé. On ne voit pas clairement de niveau d'usage sur ces sols. 


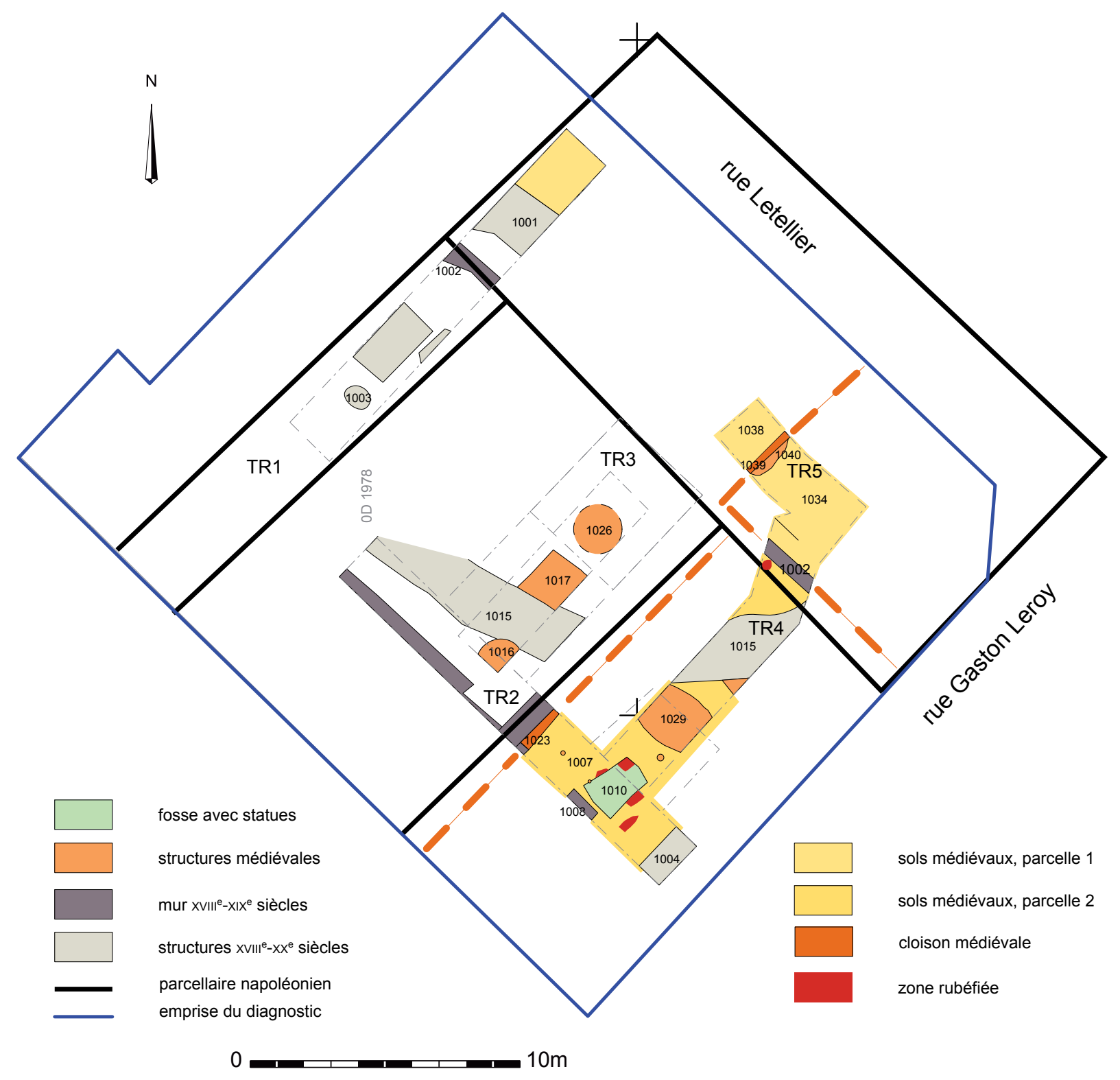

FIg. 4. - Plan général du diagnostic. Levé topographique F. Auduit, DAO L. Debs.

Vers l'ouest, une cloison rectiligne perpendiculaire à la limite de parcelle est matérialisée par un solin de blocs de grès qui devait supporter une poutre sablière. Le sol au-delà de cette cloison apparaît $10 \mathrm{~cm}$ plus haut, il y avait vraisemblablement une marche à l'intérieur du bâtiment à moins qu'il ne s'agisse d'une construction mitoyenne (fig. 5).

Le mobilier recueilli sur ces sols est peu abondant, il provient de la surface du sol le plus récent et peut être daté du XIV ${ }^{\mathrm{e}} \mathrm{s}$. La marche, elle, est comblée par un remblai contenant du mobilier de la première moitié du XIV ${ }^{\mathrm{e}} \mathrm{s}$.
La propriété située le long de la rue Gaston Leroy mesure 20 par $16 \mathrm{~m}$. Le bâtiment en front de rue est visiblement d'un seul tenant; le sol de la dernière phase se suit sur la tranchée 2 et la tranchée 4 sans autre interruption que des tranchées postérieures. Le mur arrière est matérialisé par une tranchée de pillage large de $20 \mathrm{~cm}$ dans la tranchée 2 , au-delà de laquelle on ne trouve plus de sol en terre battue. On peut estimer la taille de la construction à $16 \mathrm{~m}$ en façade et $8 \mathrm{~m}$ en profondeur.

La stratification de ce bâtiment, vue partiellement en raison des arrivées d'eau, est composée d'au moins 


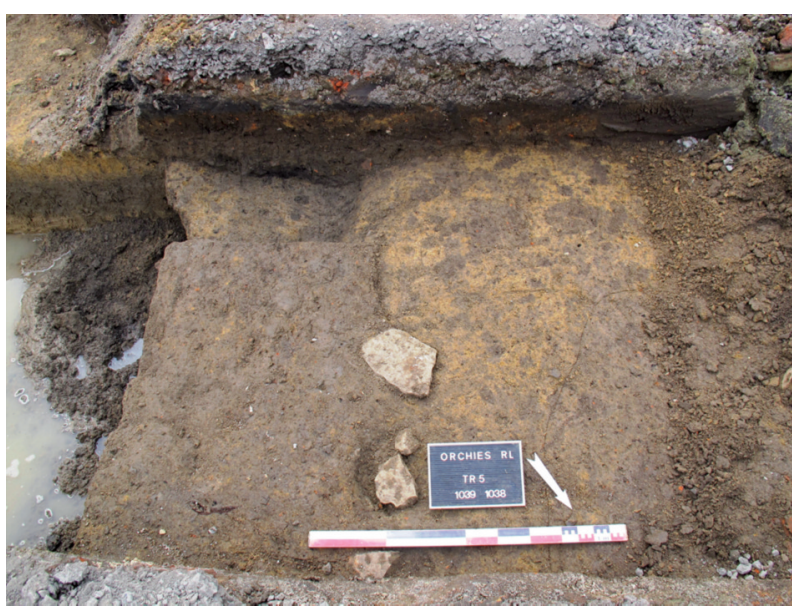

FIG. 5. - Sols médiévaux et cloison sur solin de grès dans la tranchée 5. Cliché L. Debs, Inrap.

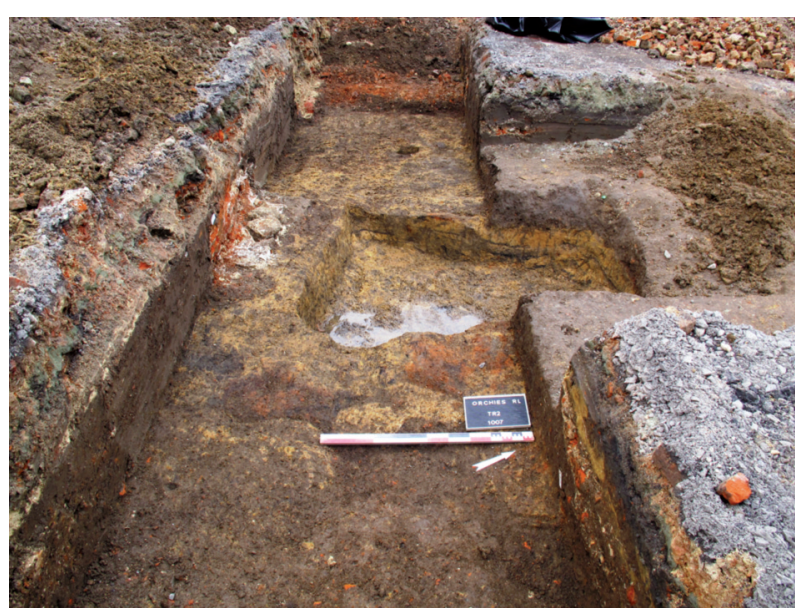

Fig. 6. - Sols médiévaux dans la tranchée 2. Cliché L. Debs, Inrap.
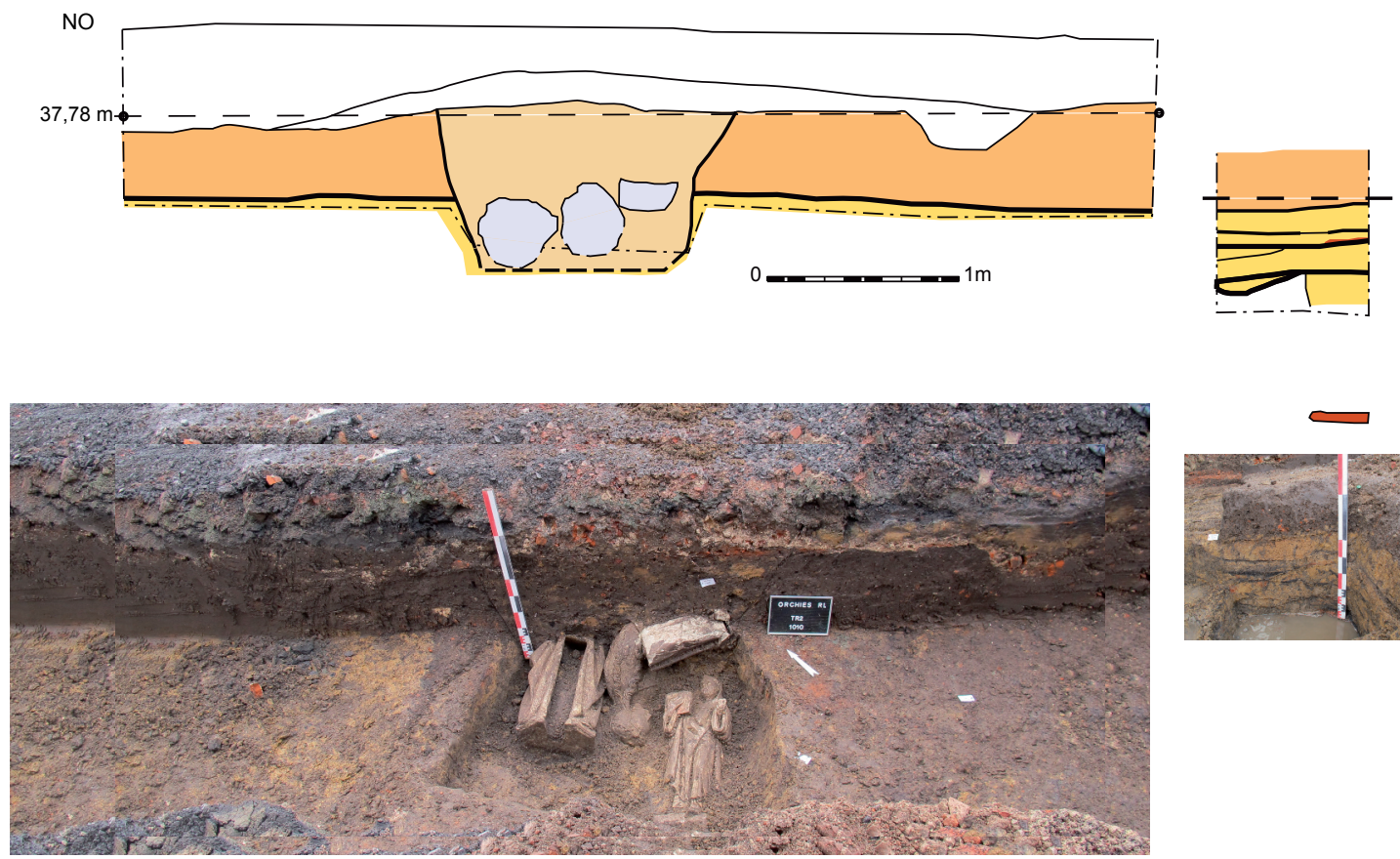

remblai 1006 , remise en culture à la fin du Moyen Âge ?
sols médiévaux
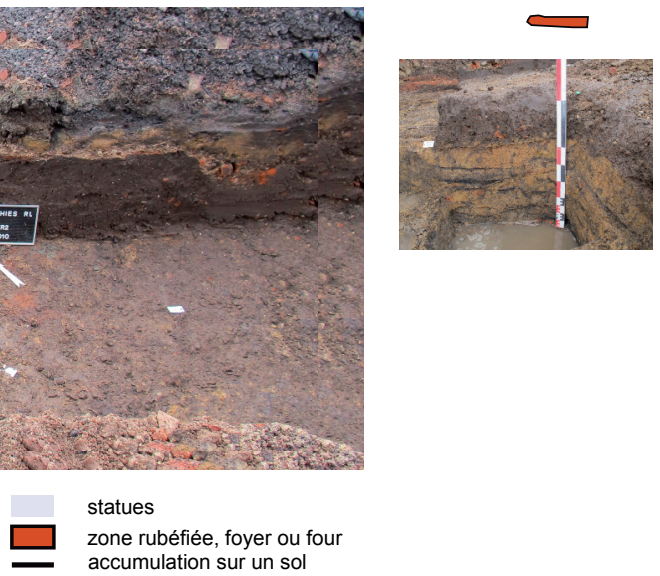

fosse avec statues accumulation sur un sol

FIG. 7. - Coupe dans la tranchée 2. Levés et clichés V. Vincent, DAO L.Debs. 
$60 \mathrm{~cm}$ de niveaux de sols successifs. Ces sols sont faits de terre battue constituée de limon jaune présentant des traces visibles de réfections (fig. 6). Chacune des trois grandes phases de sols repérées est surmontée d'une couche noire correspondant à une accumulation de salissures sur ce sol. Plusieurs zones rubéfiées correspondant à des foyers ont été repérées. Un sondage manuel pratiqué dans ces sols à l'angle des tranchées 2 et 4 a permis d'atteindre, sous le niveau d'eau, une plaque rubéfiée plus épaisse et indurée qui pourrait appartenir à un four (fig. 7).

Une fosse quadrangulaire (1029) s'ouvre à la surface des sols. Son fond est plat; il n'a pas été possible de déterminer si cette fosse est en lien avec l'utilisation du bâtiment, mais le comblement de 1029 déborde sur le sol et possède les mêmes caractéristiques que la couche scellant l'abandon des bâtiments. Cela laisse supposer que la fosse est comblée au moment où le bâtiment est détruit.

Aucun indice ne nous est parvenu sur la destination de cette construction. On trouve de nombreuses traces infimes d'oxyde d'alliage cuivreux sur le dernier sol associées à des taches de rubéfaction qui évoquent une activité artisanale. La présence d'une fosse fonctionnant avec les sols à l'intérieur du bâtiment pourrait également être liée à cette activité. La céramique recueillie sur le sol le plus récent et dans le sondage est datée du XIV ${ }^{\mathrm{e}} \mathrm{s}$.

À l'arrière de ces bâtiments, la stratigraphie est faite de couches de terre végétale et de remblais dans lesquels s'ouvrent des fosses dépotoirs. Trois de ces fosses datant du Moyen Âge ont pu être repérées et échantillonnées. Les comblements de ces fosses les datent entre le XIII ${ }^{\mathrm{e}}$ et le $\mathrm{XIV}^{\mathrm{e}} \mathrm{s}$.

Vers la fin du XIV ${ }^{\mathrm{e}}$ s., l'ensemble des bâtiments est détruit. Leur démolition est scellée par une couche de remblais ne présentant pas de grandes différences d'une parcelle à l'autre. Elle contient de nombreux fragments d'argile brûlée qui pourraient témoigner d'un incendie ayant ravagé le quartier, ce qui expliquerait que les deux propriétés apparemment distinctes, semblent disparaître au même moment. Orchies a connu plusieurs grands incendies, 1341, 1414 et 1474 pour ne citer que ceux qui entrent dans la période chronologique du remblai de démolition. S'ensuit vraisemblablement une période assez longue où le site reste vide. L'aspect du remblai brassé et homogénéisé suggère que le terrain est cultivé, ce qui correspond bien à ce qu'on voit de la parcelle sur le plan de 1570 .

\subsection{Le site aux époques moderne et contemporaine}

Plusieurs murs de briques qui ne semblent pas antérieurs au XVIII ${ }^{\mathrm{e}} \mathrm{s}$. ont été retrouvés. Le mur 1002 trouvé dans les tranchées 1 et 4 , sépare en deux la parcelle 485 du cadastre de 1817 . Il est vraisemblablement lié au mur 1008 d'axe nord-sud trouvé dans la tranchée 2, qui correspond à l'arrière d'un bâtiment représenté sur ce cadastre. Ces deux murs sont presque exactement à l'emplacement de murs médiévaux. Le comblement de la tranchée de fondation de 1002 a livré cent cinquante-deux fragments de céramique issus des rebuts d'un atelier de potier du XVII' $\mathrm{s}$.

Plusieurs fosses modernes et contemporaines ont été retrouvées dans la parcelle. Outre la fosse contenant les statues dont il est amplement question plus bas, on note un creusement d'axe est-ouest vu dans les tranchées 2,3 et 4 (1015). Il s'agit d'une tranchée courbe de 1,5 m de large et de 1,6 m de profondeur, qui a été suivie sur $15 \mathrm{~m}$ de long. Dans son comblement essentiellement constitué de gravats se trouvaient des paquets de petits fragments de céramiques agglomérés à de l'argile de potier. Ces tessons se sont révélés être des rebuts de la fabrique Lherminé installée à Orchies en 1886. La présence de cette tranchée qui prend en écharpe une bonne partie du terrain indique clairement qu'à la fin du XIX $^{\mathrm{e}}$ ou au début du $\mathrm{XX}^{\mathrm{e}} \mathrm{s}$., le terrain est à nouveau vide de constructions et le reste vraisemblablement jusqu'à la date du diagnostic.

\subsection{Les statues d'Orchies, contexte de la décou- verte}

Au cours du creusement de la tranchée 2 à la pelle mécanique, durant l'enlèvement de la couche de jardin post-médiéval, des blocs de calcaire sont apparus dans une fosse visiblement assez récente puisqu'elle coupe les sols médiévaux et le remblai d'époque moderne. Ce n'est qu'en nettoyant le fond de tranchée au niveau du sol médiéval que Vaiana Vincent a remarqué que le bloc subsistant était sculpté.

Une rapide recherche dans le tas de déblais a permis de retrouver ce qui était visiblement une partie du torse d'une statue d'ecclésiastique dont la tête avait disparu anciennement. Un sondage a donc rapidement été réalisé dans la fosse permettant de déterminer que le fragment de statue trouvé dans les déblais et celui vu en surface appartenaient à une même pièce, mais aussi de faire apparaître une autre statue sous celle-ci.

La partie de la fosse située dans la tranchée a donc été ouverte complètement, permettant de mettre au jour quatre statues dont deux seulement étaient visibles en totalité, les deux autres étant partiellement sous la coupe. 


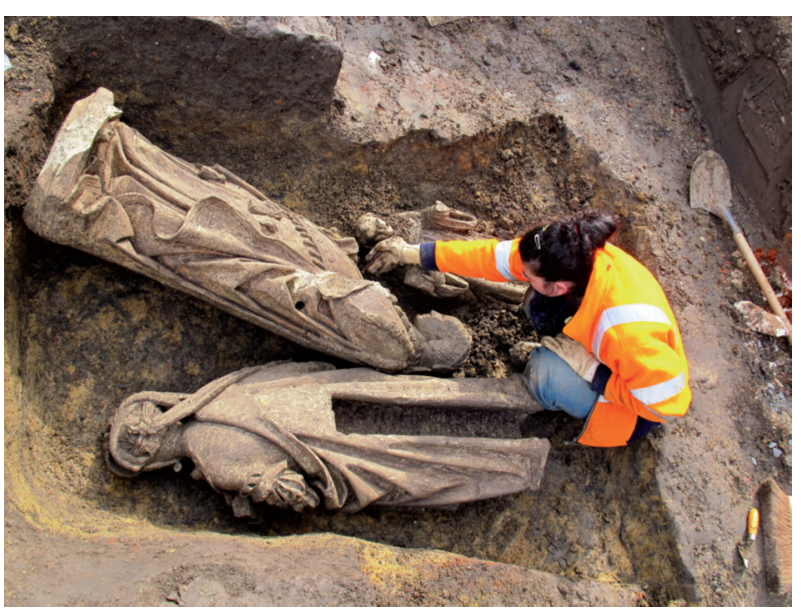

FIG. 8. - Fouille de la fosse 1010.

Cliché L. Debs, Inrap.

L'importance de cette découverte dépassant ce que l'on peut attendre lors d'un diagnostic classique, il a été décidé, après consultation du Service régional de l'Archéologie et de l'Inrap de fouiller complètement la structure et d'organiser le transport des statues au centre de recherches archéologiques de Villeneuved'Ascq dans les plus brefs délais. Dans le même temps, du matériel de protection était apporté sur le terrain. Une fois la couverture photographique et le relevé de coupe terminés, le sondage a donc été partiellement rebouché et sécurisé pour la nuit. Le lendemain, l'emprise de la fosse 1010 ayant été entièrement dégagée à la pelle mécanique, la fouille a permis de mettre au jour les statues (fig. 8) et de procéder à leur enregistrement (plan, photo...). Les statues étaient désormais vulnérables et il était impossible de sécuriser la fosse pour la nuit. Alertée de cette découverte, la brigade de gendarmerie d'Orchies a assuré la surveillance du site durant la nuit. Enfin, le jour suivant, un camion-grue permettait de sortir les statues.

\subsection{La fosse 1010}

La fosse dans laquelle ont été trouvées les statues est un rectangle de 2,2 par $1,5 \mathrm{~m}$, profond de $90 \mathrm{~cm}$ aux parois sub-verticales sur une trentaine de centimètres s'évasant dans la partie haute, dont l'encaissant est moins cohérent. Son comblement (1011) est constitué de terre végétale, de nombreux fragments d'argile brûlée et de grosses boules d'argile jaune. On y distingue facilement un mélange des terres dans lesquelles la fosse a été creusée: les sols médiévaux et le remblai les surmontant. La fosse a donc vraisemblablement été comblée peu de temps après son creusement avec les matériaux d'origine.

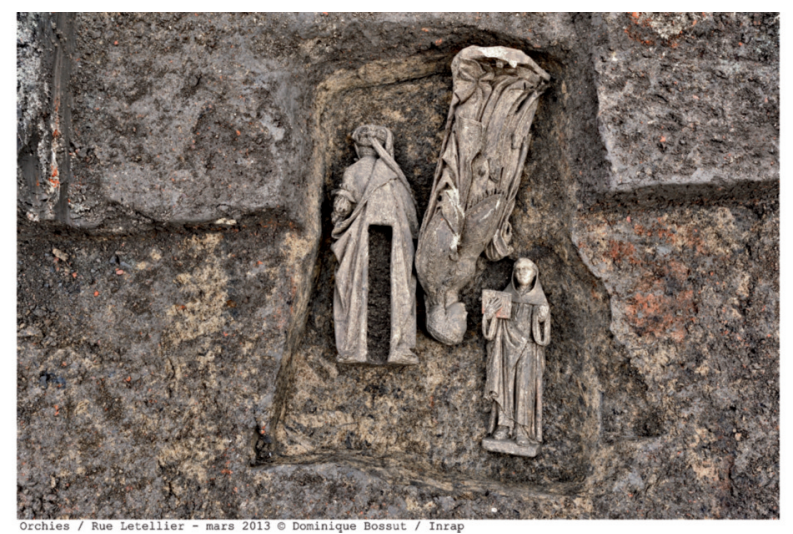

FIG. 9. - La fosse 1010.

Cliché D. Bossut, Inrap.

Contre les bords de la fosse, quelques traces brunes suggèrent que du bois a pu être posé pour maintenir les parois, mais les traces sont trop ténues pour déterminer s'il s'agit d'un cuvelage ou juste de quelques planches posées rapidement.

Trois des statues sont posées sur le fond de la fosse (fig. 9). Celle de Marie-Madeleine est face contre le sol, le long de la paroi nord. Elle a pu être identifiée au moment de son enlèvement grâce à son attribut habituel, la boîte à nard dont elle oignit les pieds de Jésus, qu'elle présente dans sa main droite, tandis qu'elle tient un livre de la main gauche. Elle mesure $123 \mathrm{~cm}$. Le personnage est debout sur un socle octogonal. La statue est pratiquement intacte à l'exception de quelques plis cassés de la robe.

Posée légèrement en biais dans la fosse, la statue de sainte Agnès est sur le côté droit, son épaule gauche est appuyée sur la statue de Marie-Madeleine (fig. 10). La sainte est représentée debout sur un socle octogonal. Elle mesure $142 \mathrm{~cm}$. Sainte Agnès est généralement représentée avec un agneau s'appuyant sur ces jambes. Il ne reste de l'agneau que les sabots, deux sur le socle, deux autres sur le drapé du manteau à gauche, ainsi qu'un tenon rectangulaire au niveau du corps de l'animal. Cette cassure est antérieure à l'enfouissement. Seule la main droite est présente, à laquelle il manque deux doigts. La main gauche, cassée anciennement, elle aussi, semble avoir été réparée: un trou de tenon traverse le poignet. Elle n'a pas été retrouvée: peut-être la pièce rapportée était-elle en bois. Le poignet gauche était situé juste sous la quatrième statue qui a appuyé dessus et l'a brisé au cours du terrassement.

Une statue de taille plus réduite $(97 \mathrm{~cm})$ est également posée sur le dos au fond de la fosse, dans l'angle 


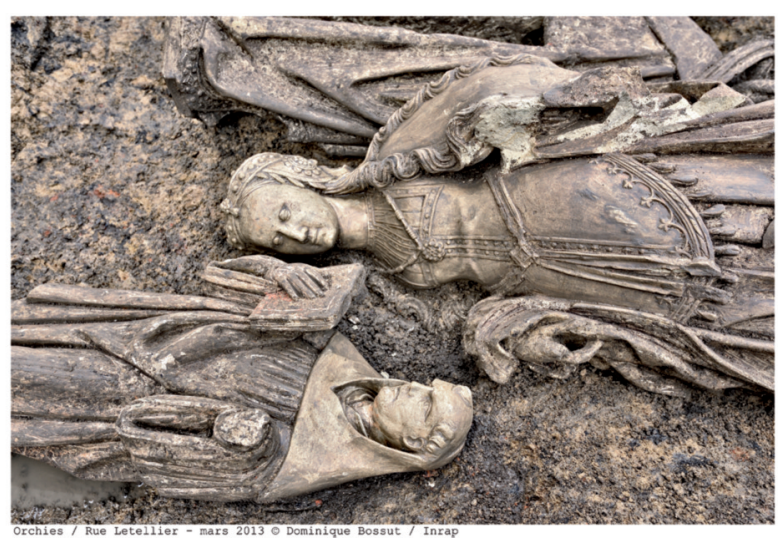

FIG. 10. - Statues de sainte Agnès et d'un des moines in-situ. Cliché D. Bossut, Inrap.

sud. Elle représente un moine au visage sévère coiffé d'une capuche. Dans la main droite, il tient un livre ouvert; la main gauche est manquante.

La quatrième statue a été déposée plus haut dans la fosse, elle est couchée de biais et repose en partie sur celle de sainte Agnès. Il est difficile de dire si les deux statues se touchaient dès l'enfouissement. Couchée sur le dos, elle a été fortement touchée par le godet de la pelle mécanique et brisée en trois morceaux. Elle représente un moine, dont les mains ont disparu anciennement. La tête est absente, un clou fiché dans le cou laisse penser qu'elle a été cassée et remplacée par une pièce rapportée, peut-être en bois, qui a disparu depuis.

La découverte de ces statues pose de multiples questions. La première est celle de leur provenance. Il existe à Orchies, on l'a vu, quatre établissements susceptibles d'avoir abrité ces œuvres: l'église SaintVaast et le couvent des Capucins intra-muros, l'hôpital Notre-Dame de Théomolin et le couvent des Sœurs Grises à l'extérieur. Le site est presque à égale distance du couvent des Capucins et de l'église paroissiale. La présence de deux statues de moines dont l'un pourrait être un Franciscain semble plaider en faveur du couvent des Capucins, mais les deux statues de saintes semblent antérieures à la fondation de l'ordre, a fortiori à son implantation à Orchies. Restent donc l'église et les deux établissements extérieurs pour lesquels, pour le moment, aucune mention de statuaire ou de chapelle consacrée à l'une des saintes n'a été retrouvée. La question sur ce sujet n'a donc pas de réponse à ce jour.

La façon dont les statues ont été installées dans la fosse apporte des indices sur la nature de ce dépôt.
Les statues ont été mises intactes dans la fosse, les cassures sont anciennes et aucun fragment n'a été trouvé dans le comblement qui pourrait indiquer qu'il y a eu des dégâts au moment de leur enfouissement hormis peut-être quelques parties très fragiles du plissé des robes des deux saintes. Quelqu'un s'est donc donné la peine de les transporter depuis un édifice relativement éloigné (les plus proches sont à plus de $200 \mathrm{~m}$ ) et de les mettre dans une fosse creusée à cet effet sans les endommager. On a donc l'impression que les statues pourraient avoir été mises dans la fosse pour les préserver plus que pour s'en débarrasser, ou au moins que, si elles ont été jetées, elles l'ont été de façon assez respectueuse. Pour autant, la façon dont les statues sont installées dans la fosse, l'une face contre terre, une autre sur le côté et partiellement appuyée sur la première, montre qu'elles n'ont pas non plus été installées de façon très ordonnée ce qui s'explique notamment par le poids des statues de saintes difficiles à manipuler. L'aspect des bords de la fosse et du comblement indique par ailleurs que l'enfouissement et la fermeture de la fosse ont été assez rapides.

Cette précipitation fait évidemment penser à une cache dans laquelle les statues auraient été mises à l'abri durant une période troublée puis oubliées. La céramique trouvée dans le comblement de la fosse 1011, datée du XVIII ${ }^{\mathrm{e}}$ s., et les deux moines du XVII ${ }^{\mathrm{e}} \mathrm{s}$. permettent d'exclure la période des guerres de religion qui a donné lieu à Orchies à de violents affrontements. Les éléments de datation plaident donc en faveur d'un enfouissement au XVIII ${ }^{\mathrm{e}}$ s. et c'est naturellement à l'époque révolutionnaire que l'on pense. Les légendes d'objets du culte cachés à cette occasion et miraculeusement réapparus ne manquent pas en France et on sait qu'à Orchies, les révolutionnaires ont brûlé sur la grand-place une partie du mobilier et des ornements de l'église.

Il est donc assez tentant de penser qu'on a voulu dérober à la vindicte révolutionnaire une partie du patrimoine religieux de la ville et que le souvenir de cette cache a été perdu jusqu'à nos jours, à moins que la construction d'une maison sur la parcelle n'ait empêché leur récupération. Les bâtiments de briques trouvés sur la parcelle et qui correspondent au bâti visible sur le cadastre napoléonien viennent en effet sceller la fosse peu de temps après la Révolution.

\section{PREMIERS ÉLÉMENTS D'ANALYSE STYLISTIQUE (L. Barragué-Zouita)}

Les œuvres sont couvertes d'une pellicule de terre due à leur séjour prolongé dans un sous-sol argileux qui a permis leur très bonne conservation: les zones 


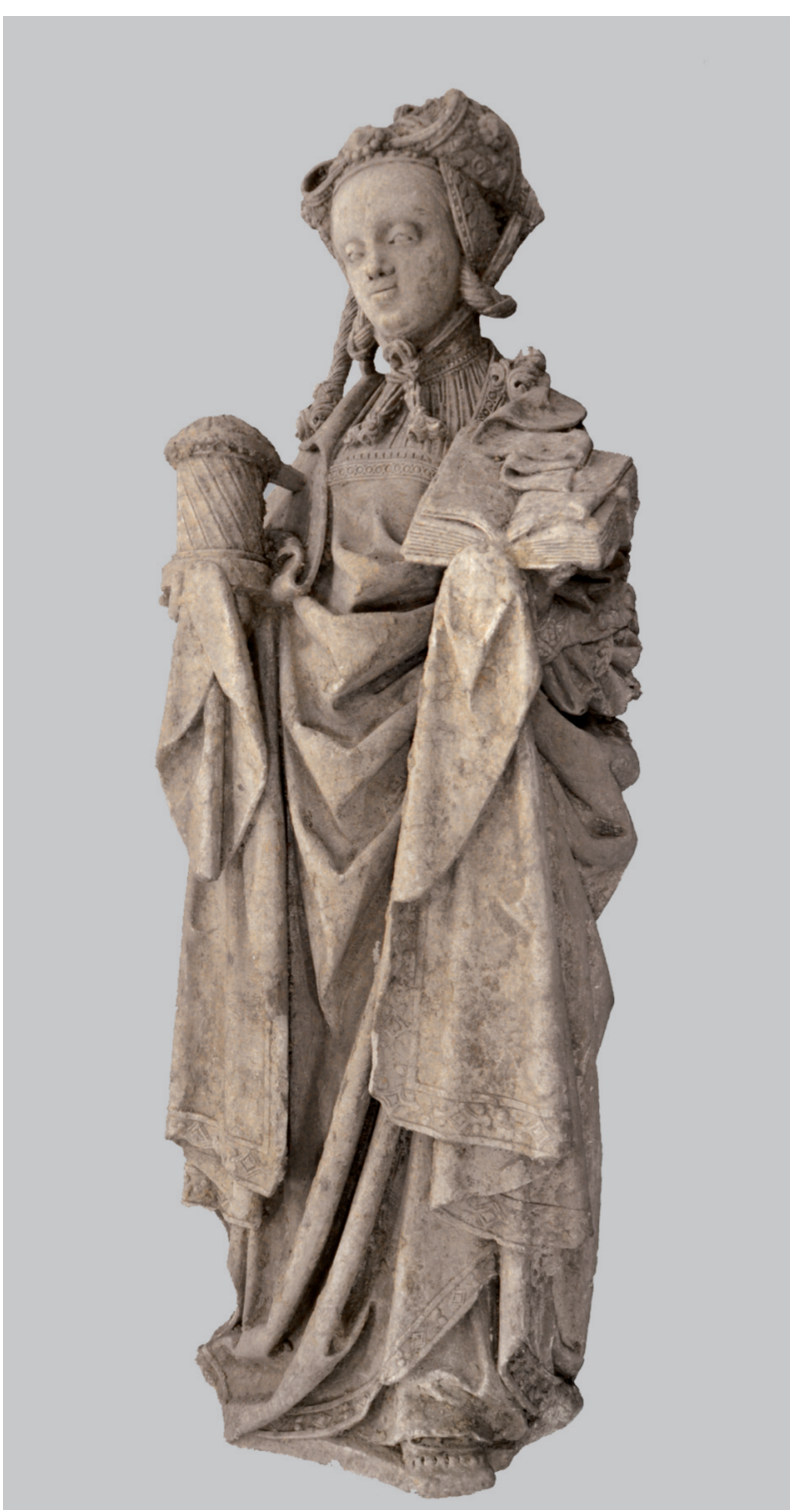

FIG. 11. - Statue de sainte Marie-Madeleine ( $n^{\circ}$ inv. D 2015.1.4).

de fragilité de la pierre sont circonscrites, à l'exemple du bras senestre de la statue de sainte Anne. Compte tenu de leur état, il est délicat de proposer une étude approfondie de ces œuvres dont la restauration est prévue en 2016; quelques remarques relatives à la mise en œuvre et au style de chaque sculpture peuvent cependant être formulées.

Les deux figures féminines, d'une qualité indéniable, sont exécutées dans un calcaire très fin à glau-

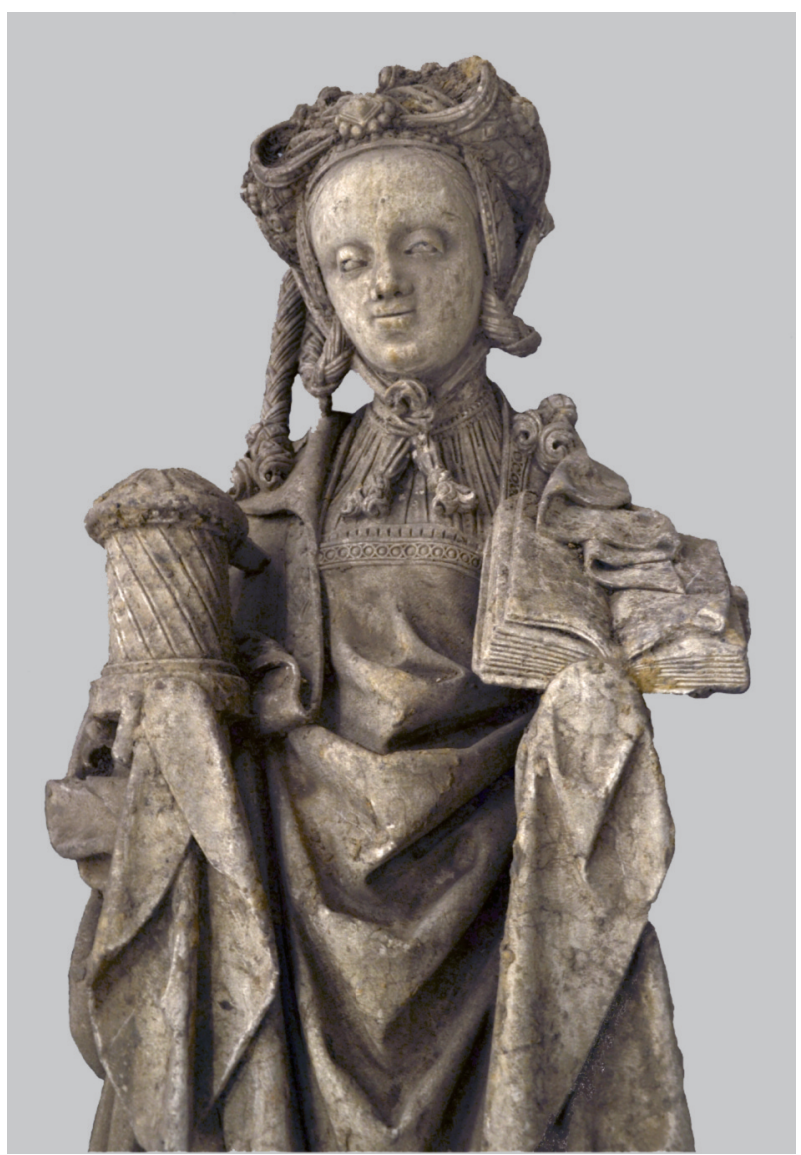

FIG. 12. - Statue de sainte Marie-Madeleine, détail de la partie supérieure.

conies qui s'apparente au calcaire de l'Avesnois ${ }^{9}$. Les différences notables de mise en œuvre et de style indiquent qu'elles n'ont pas été conçues pour le même ensemble décoratif.

La figure de Marie-Madeleine (fig. 11 et 12) présente un très bon état de conservation à l'exception de quelques lacunes et épaufrures sur les parties les plus saillantes. L'œuvre est sculptée au revers jusqu'au milieu du dos, puis évidée dans sa partie inférieure: elle devait être conçue pour être présentée contre un mur ou un pilier. La sainte est richement vêtue: elle porte un ample manteau recouvrant son épaule droite et ses deux mains, une robe à encolure carrée et une chemise décrivant un plissé sur la poitrine jusqu'au cou. Les détails du costume sont très soignés, comme en témoignent les galons de la robe et du manteau, la manche senestre à bouillons (sur laquelle des traces de polychromie gris et or ont été relevées), la chaus-

9. - Observations faites avec 1'aide de Sabine Kessler et Julie AndréMadjlessi, restauratrices. 


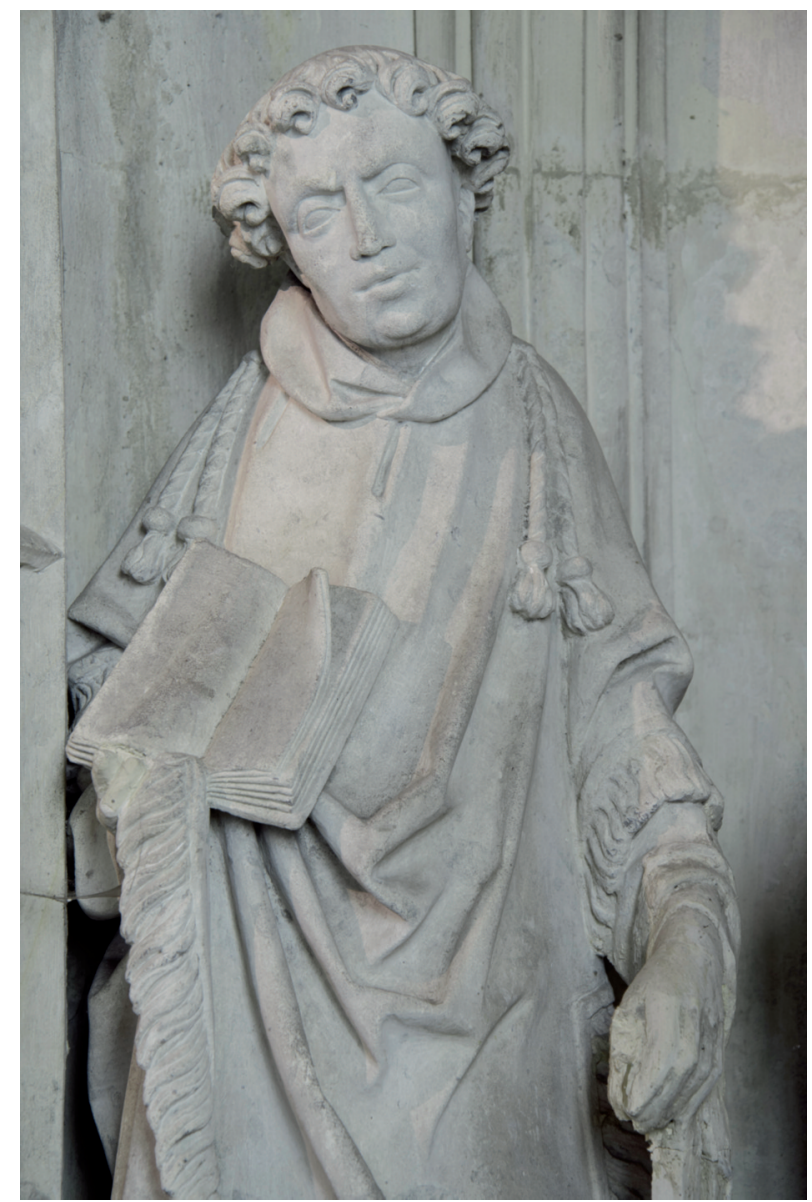

FIG. 13. - Horrues (Belgique), église Saint-Martin, retable de saint Hubert, détail de la statue de saint Étienne.

sure à crevés dépassant de la robe. Il en est de même pour les attributs de Marie-Madeleine: le pot à onguent imite l'orfèvrerie avec un décor de godrons torsadés, tandis que le livre, dont l'une des pages est en train de se soulever, est muni d'un fermoir métallique. La coiffe, particulièrement élaborée, comporte un turban agrémenté d'éléments décoratifs en métal, maintenu par un ruban noué sous le menton; deux longues tresses s'en échappent.

Cette œuvre à la facture très maîtrisée présente une attitude générale assez souple, un traitement ample des drapés qui alternent plis en triangle superposés et plis tubulaires. Le visage, de forme triangulaire, se caractérise quant à lui par un nez court, des lèvres charnues et des yeux écartés, légèrement tombants, en forme de croissant sous des paupières très bombées.
Ces traits permettent de rapprocher la statue de certaines productions hennuyères des années 1520 . Plusieurs sculptures attribuées à la région de Mons ou à des sculpteurs brabançons actifs dans la région montoise présentent des parentés avec l'œuvre orchésienne ${ }^{10}$, en particulier les figures d'apôtres, aux dimensions plus réduites (environ $65 \mathrm{~cm}$ ) du retable de saint Hubert de l'église Saint-Martin d'Horrues (fig. 13). Le modelé fin du visage, l'attention au décor des vêtements et le traitement du livre (présenté au spectateur et isolé de la main par un pan du manteau) plaident en faveur d'un tel rapprochement. Cependant la figure de Marie-Madeleine présente des traits singuliers pour lesquels nous n'avons pas encore identifié d'équivalents: le front bombé et le traitement très creusé des orbites ne se retrouvent pas dans les sculptures de ce groupe, exécutées par un autre sculpteur ou atelier.

La statue de sainte Agnès (fig. 14), dont l'état de conservation est satisfaisant, présente des lacunes plus importantes (main gauche, agneau appuyé sur sa jambe gauche). Quelques traces de polychromie et de préparation ont été relevées dans les creux des plis, sur le flanc dextre et la base. L'œuvre était prévue pour être placée contre un mur à une certaine hauteur, ainsi que le suggère le mouvement de la tête vers le bas et le dos plat non sculpté, seulement creusé de deux cavités. Le costume, à l'instar de celui de MarieMadeleine, est très détaillé. Le manteau, qui recouvre l'épaule à senestre, laisse apparaître un surcot à l'encolure carrée, agrémenté de pompons en partie inférieure et d'un galon perlé; ce même motif se retrouve sur la chemise plissée visible sur le buste et montant au ras du cou. Une ample jupe descend jusqu'aux pieds. Les éléments de parure sont soignés, tels le collier à pendentif et le demi-ceint (ceinture) à longs rubans. La coiffe à décor métallique comporte des fleurs sur les oreilles, des pendants en formes de feuilles et une petite fleur sur le front, au centre du bandeau. Les cheveux de la sainte décrivent de longues mèches ondulées.

L'œuvre est de belle qualité: le léger hanchement décrit une ligne serpentine qui se poursuit par l'inclinaison de la tête dans le prolongement du cou. Le costume, très détaillé, alterne plages lisses et volumes importants. Le surcot, la coiffe et le haut du bras à senestre sont exécutés suivant un relief peu accentué, qui met l'accent sur la précision du dessin. La quasiabsence de plis sur le surcot rend compte de l'épaisseur et de la rigidité du tissu utilisé. Le bras dextre 


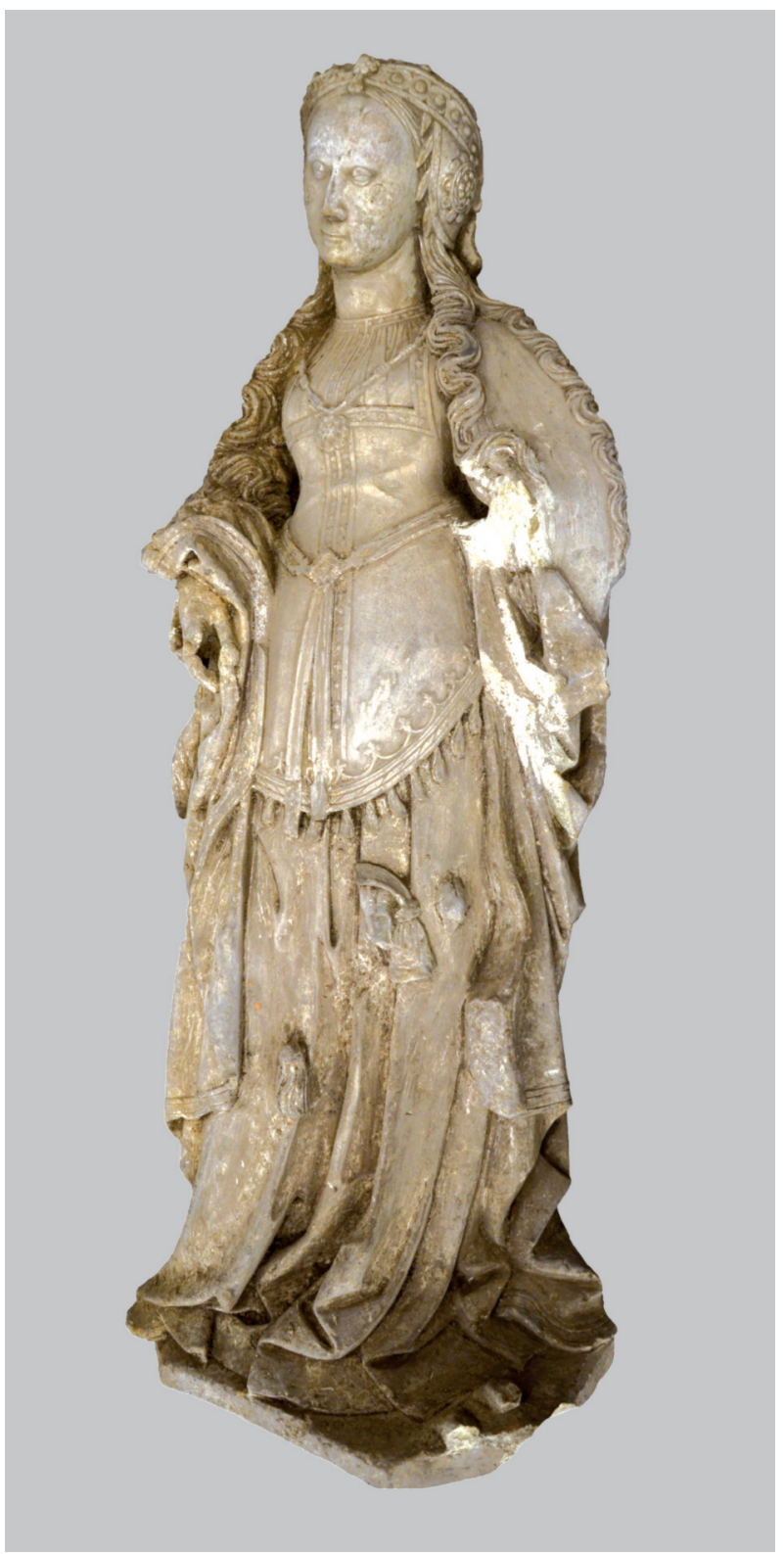

FIG. 14. - Statue de sainte Agnès ( $n^{\circ}$ inv. D 2015.1.3).

témoigne d'une toute autre facture: la multiplication des mouvements d'étoffes aux manches et l'attitude très souple de la main lui confèrent une ampleur et un dynamisme importants. Le travail, finement exécuté, permet de rompre l'aspect linéaire des plis sur la partie inférieure du vêtement. Le visage du personnage, inscrit dans un ovale, se distingue par un nez long et assez large, de petits yeux mi-clos et une bouche étroite. Si la datation de cette pièce aux alentours de 1520-1530 est très probable, nous ne sommes pas parvenus à l'heure actuelle à trouver d'analogies pro-

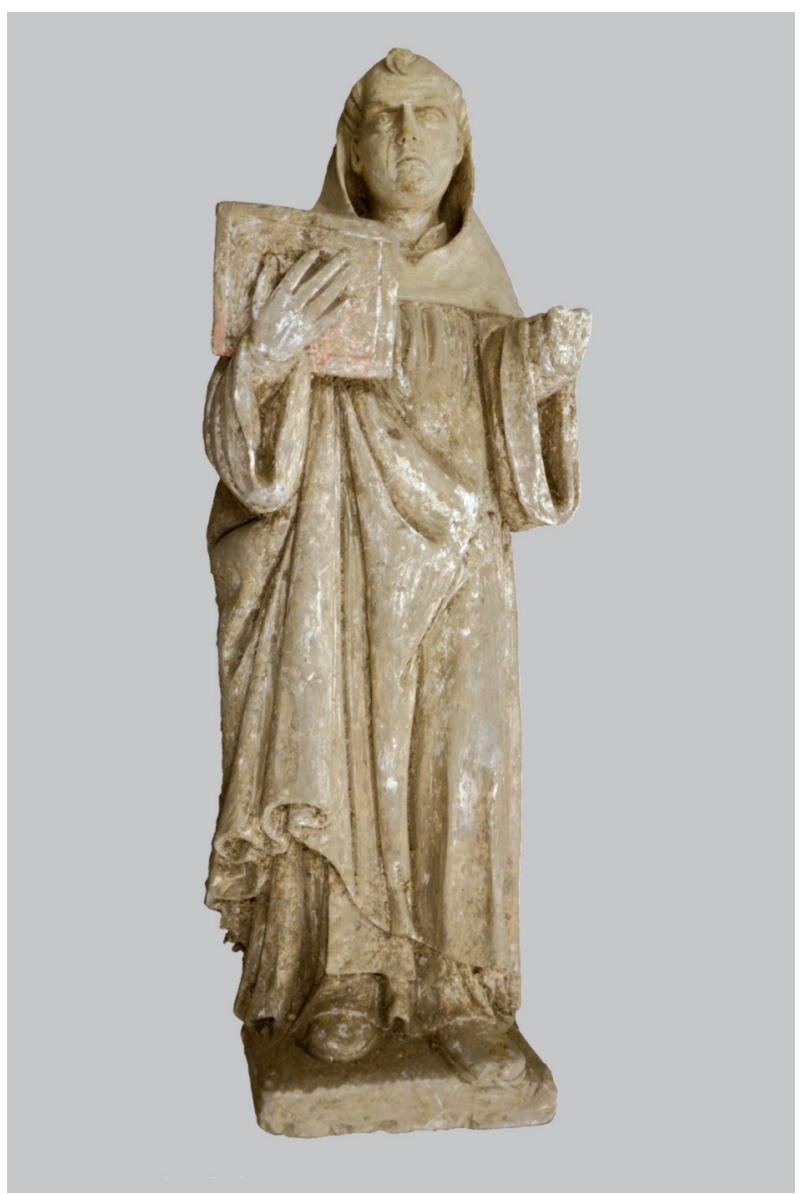

FIG. 15. - Statue du moine ( $n^{\circ}$ inv. D 2015.1.2).

bantes qui permettraient de la rattacher à un foyer de production précis. Une influence brabançonne est néanmoins sensible dans l'exubérance décorative du costume.

Les sculptures de deux saints moines, aux dimensions plus réduites, sont de qualité plus sommaire. Leurs caractéristiques nous incitent à les faire remonter à la seconde moitié du XVI $\mathrm{e}$ s. ou au XVII $\mathrm{e}$.

La première d'entre elles, haute de $97 \mathrm{~cm}$, est en bon état de conservation (fig. 15). Elle a conservé des traces significatives de polychromie: en particulier du rouge sur le livre, et de la dorure sur le vêtement; trois couches successives sont visibles, la dernière consistant en un badigeon blanchâtre. Le personnage arbore un visage sévère, aux traits marqués. Vêtu d'une tunique à amples manches et d'une capuche partiellement relevée, il porte un livre de la main dextre, et a perdu l'autre main. Une petite cavité creusée dans le pied indique qu'il tenait probablement un bâton ou 


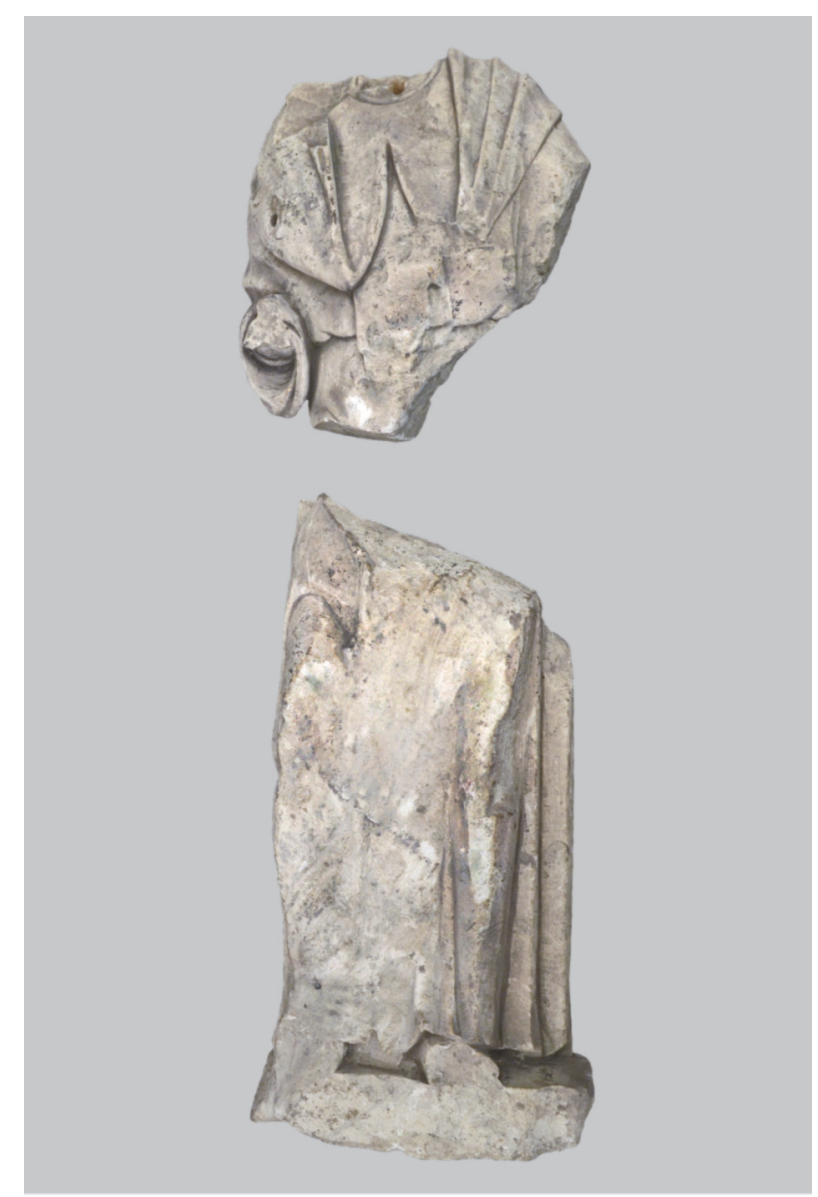

FIG. 16. - Fragments d'une statue de saint moine (ninv. D 2015.1.1).

une crosse. Le sculpteur a su imprimer un certain dynamisme à sa représentation par le déhanchement de la statue, dont l'un des pieds est plus avancé sur le socle, et par le mouvement du manteau.

La dernière statue, abîmée au moment de la découverte, est très fragmentaire (fig. 16). Aux deux fragments les plus importants s'ajoutent un troisième élément provenant de la base de la sculpture et quelques fragments issus du revers. Cette figure monastique, également vêtue d'une tunique munie d'une capuche, devait présenter une taille comparable à celle de l'œuvre précédente; les drapés sont cependant traités de manière plus linéaire.

L'étude puis la restauration de ce groupe au sein du Palais des Beaux-Arts de Lille permettront très certainement d'en apprendre davantage sur la mise en œuvre des quatre sculptures. Ces interventions sont également un préalable indispensable à une analyse stylistique plus approfondie des statues, que nous pouvons raisonnablement considérer comme des productions régionales. La recherche de sources historiques et iconographiques complémentaires devra être poursuivie afin de mieux connaître le contexte de production et la destination de chacune des œuvres composant cet ensemble exceptionnel.

\section{LA CÉRAMIQUE MÉDIÉVALE ET MODERNE D'ORCHIES (V. Vincent)}

La céramique découverte sur le diagnostic d'Orchies constitue un assemblage important, au vu de la surface ouverte. Celui-ci s'élève à 1399 tessons pour 439 individus identifiés. Plusieurs ensembles spatio-chronologiques peuvent se distinguer: celui des niveaux de sol et jardin proprement médiévaux, la tranchée de fondation 1002 en tranchée 1 datant du $\mathrm{XVII}^{\mathrm{e}}$ s., le matériel issu de la fosse des statues du $\mathrm{XVIII}^{\mathrm{e}} \mathrm{s}$. et enfin la tessonnière du $\mathrm{XIX}^{\mathrm{e}} \mathrm{s}$. Le taux de fragmentation est assez important notamment dans les tessonnières des $\mathrm{XVII}^{\mathrm{e}}$ et $\mathrm{XIX}^{\mathrm{e}} \mathrm{s}$. Les tessons ont été pilés, sans doute dans un but de drainage des structures supérieures. Certains éléments sont même agglomérés entre eux avec du mortier blanc. Le reste du mobilier présente une bonne conservation, sans élément notable.

\subsection{Méthodologie}

Les lots céramiques ont été comptés par unités stratigraphiques d'après un tableau de comptage individualisant les lèvres $(\mathrm{L})$, panses $(\mathrm{P})$, fonds $(\mathrm{F})$, éléments de préhension (EP) et les éléments verseurs (EV) par catégorie. Les catégories céramiques sont définies à partir de différences techniques de l'objet. Sont pris en compte:

- la technique de façonnage: la majorité du matériel est ici tournée
à l'exception du fragment de céramique dite «à dégraissants cal-
caires », modelée puis tournassée;
- le type de cuisson: on distingue ainsi la cuisson réductrice, la
cuisson oxydante et celle portée à très haute température comme
les grès;
- le mode de décor: on identifie les différents traitements de sur-
face, comme l'apposition d'une glaçure, d'un engobe ou d'un
décor à la corne par exemple.

La base du comptage repose sur le nombre de reste (NR) et le nombre minimum d'individus (NMI). Le NMI a été déterminé uniquement à partir des lèvres, après recollage de celles-ci ${ }^{11}$. Chaque individu a ensuite été isolé et un numéro d'inventaire lui a été 


\begin{tabular}{lrrrr}
\hline & \multicolumn{2}{c}{ P1 } & \multicolumn{2}{c}{ P2 } \\
\hline & NR & \% NR & NR & \% NR \\
\hline TCG & 306 & $90,2 \%$ & 369 & $86,8 \%$ \\
\hline TCR & 4 & $1,2 \%$ & 19 & $4,5 \%$ \\
\hline TCR-gl & 16 & $4,7 \%$ & 23 & $5,4 \%$ \\
\hline TCR-gl/eng & 8 & $2,4 \%$ & 9 & $2,1 \%$ \\
\hline TCR-gl/HD & 4 & $1,2 \%$ & 1 & $0,2 \%$ \\
\hline TCB-gl & 1 & $0,3 \%$ & 1 & $0,2 \%$ \\
\hline TCRosée-gl & 0 & $0,0 \%$ & 1 & $0,2 \%$ \\
\hline grès & 0 & $0,0 \%$ & 1 & $0,2 \%$ \\
\hline TCGcalc & 0 & $0,0 \%$ & 1 & $0,2 \%$ \\
\hline Total & 339 & $100,0 \%$ & 425 & $99,8 \%$ \\
\hline
\end{tabular}

Tableau 1. - Les catégories céramiques des phases 1 et 2, Moyen Âge. Nombre de restes et pourcentage.

attribué, du type $n^{\circ} U s-1$ à $n$. Ont été définis ensuite la forme et le type auxquels il correspond. Pour ce faire, une typologie propre au chantier d'Orchies a été déterminée. La détermination chronologique a été établie à partir d'observations techniques, de comparaisons morphologiques, et en adéquation avec les relations stratigraphiques et dont sont issus les différents lots.

\subsection{Détermination chronologique}

\subsubsection{Les niveaux médiévaux}

Le lot se compose de 764 tessons pour soixante et onze individus et se répartit principalement dans les tranchées 2, 3 et 4 au niveau des sols (tr.2 et 4), des fosses (de la tr. 3 ) et des niveaux de jardin qui viennent sceller le tout.

Deux phases se distinguent: une première, située entre la fin du XIII et le début du XIV ${ }^{\mathrm{e}} \mathrm{s}$. définie à partir du matériel découvert principalement dans des fosses et une deuxième, datée entre la fin du XIV et le début du $\mathrm{XV}^{\mathrm{e}} \mathrm{s}$. correspondant à différents niveaux de remblais et jardins.

D'un point de vue technique, la nuance est délicate (tab. 1). La production de terre cuite grise (TCG) domine largement les deux ensembles, ce qui est somme toute assez courant pour les assemblages antérieurs au $\mathrm{XV}^{\mathrm{e}} \mathrm{s}$. La terre cuite grise se constitue d'un tesson tourné, très sonnant, bien cuit, d'un gris soutenu à cœur et en surface. La pâte est fine et les inclusions invisibles à l'œil nu. On compte 90,2\% de cette production pour la première phase contre $86,8 \%$ pour la seconde. La terre cuite rouge (TCR) présente les

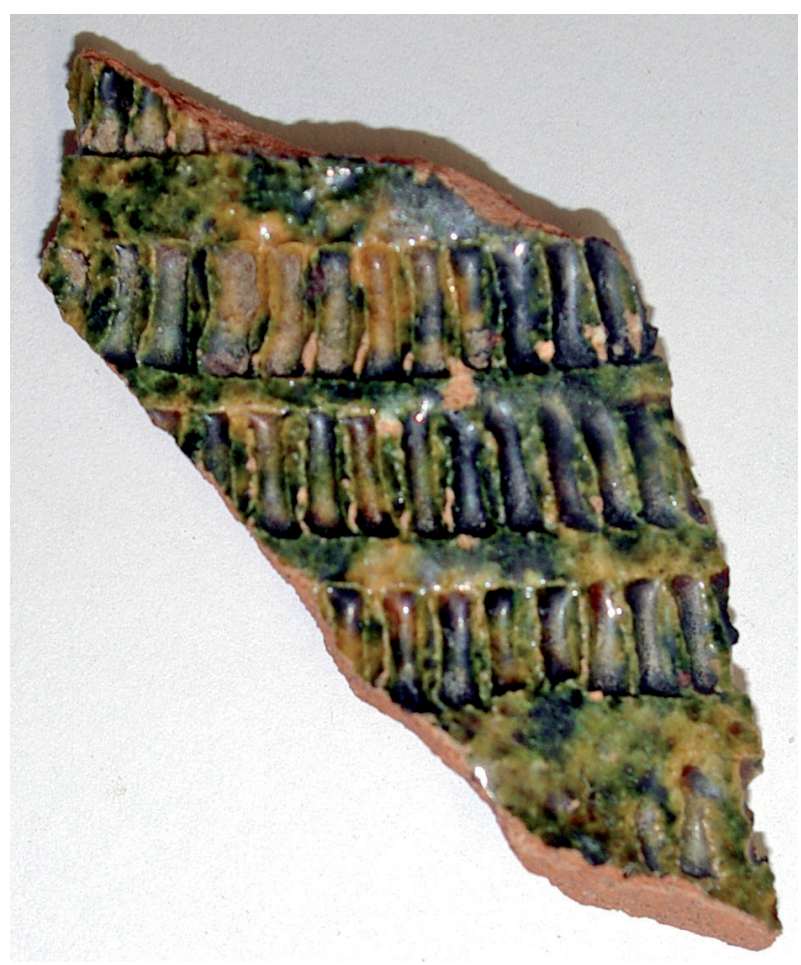

FIG. 17. - Panse de céramique "hautement décorée », US 1000, fin XIV -début $X V^{e}$ s. (C) V. Vincent.

mêmes propriétés que la terre cuite grise à savoir un tesson bien cuit et sonnant et une pâte fine d'un orange soutenu. Elle dispose de différents traitements de surface: la glaçure, ici majoritairement projetée (TCR-gl) ou l'apposition d'un engobe blanc sous la glaçure (TCR-gl/eng). L'ensemble représente 8,3\% de la première phase et $12 \%$ de la seconde. On perçoit ainsi au cours du $\mathrm{XIV}^{\mathrm{e}} \mathrm{s}$. une diminution sensible des éléments à pâte grise au profit de ceux à pâte rouge, le plus souvent glaçurés. On note aussi la présence de terre cuite rouge glaçurée dite « hautement décorée ». Il s'agit d'une céramique présentant « une combinaison d'au moins deux types de décor morphologiquement et techniquement différents $»^{12}$ comme l'a défini F. Verhaeghe au colloque de Lille en 1988. Les cinq éléments découverts ici disposent tous d'un décor à la molette sous forme d'une succession de fins rectangles espacés régulièrement, et sont recouverts d'une glaçure coulée (fig. 17). Ce type de décor est largement répandu à Douai du milieu du XII ${ }^{\mathrm{e}} \mathrm{s}$. à la première moitié du XIV ${ }^{\mathrm{e}} \mathrm{s}$., avec une diffusion plus prononcée dans la seconde moitié du XIII ${ }^{\mathrm{e}} \mathrm{s} .{ }^{13}$. Cela

12. - Verhaeghe 1989, p. 20.

13. - LOUIS 1996, p. 115. 
corrobore assez bien les proportions des deux phases, avec pour la première $1,2 \%$ et la seconde $0,2 \%$, marquant ainsi la fin du phénomène. Le fragment de panse à pâte rosée glaçurée (TCRosée-gl) peut aussi être associé aux fabriques douaisiennes. La présence de terre cuite blanche glaçurée (TCB-gl), de manière tout à fait anecdotique, rappelle quant à elle, les productions de la région de Tournai. La terre cuite grise à dégraissant calcaire (TCGcalc) est une production caractéristique du Valenciennois de P. Korpiun. Elle correspond à la fabrique 5, définie dans la synthèse sur la vaisselle et les objets médiévaux en terre cuite de Valenciennes ${ }^{14}$ : «Pâte grossière à gros dégraissant cuite en atmosphère oxydante ou réductrice. La couleur varie du brun au gris. Le dégraissant est abondant et se compose d'un mélange calcaire et coquillages broyés ». Cette production est caractéristique des $\mathrm{X}^{\mathrm{e}}$ $\mathrm{XI}^{\mathrm{e}} \mathrm{s}$. dans les ensembles découverts en cœur de ville de Valenciennes et est utilisée jusqu'à la fin du XIII ${ }^{\mathrm{e}}$ début du XIV e s. Il semble s'agir d'une production locale, propre au Valenciennois, dont des exemples de Sepmeries ${ }^{15}$ datés des $\mathrm{XI}^{\mathrm{e}}$-XII ${ }^{\mathrm{e}}$ s. ou de Saint-Amandles-Eaux ${ }^{16}$ datés du XII ${ }^{\mathrm{e}} \mathrm{s}$. peuvent être aussi mentionnés. Elle semble ici en position résiduelle. Enfin, on note la présence d'une panse de grès issue du niveau de jardin 1007, associée à la période 2, qui apparaît dans les ensembles régionaux à partir de la seconde moitié du XIV $\mathrm{s}$.

Ce sont les données morphologiques qui accentuent le plus la différence entre ces deux assemblages. La première phase reflète le spectre céramique découvert en contexte d'habitat avec de la vaisselle de table, de cuisson, de stockage, de préparation et de vie quotidienne. La vaisselle de table est représentée par une assiette (de type A1, non dessinée), douze pichets de type PI2, un pichet de type PI3 et une cruche CR1. L'assiette A1 est une assiette à marli droit très court, avec une légère inflexion à son extrémité qui caractérise assez bien les premières assiettes apparaissant dans les corpus céramiques du XIV $\mathrm{s}$. Le pichet PI2, largement représenté, à col cannelé et renflement interne dispose de multiples références dans la région et en Belgique pour les $\mathrm{XIII}^{\mathrm{e}}-\mathrm{XIV}^{\mathrm{e}}$ s. Celui-ci est secondé par le pichet PI3, à lèvre en bandeau qui peut être comparé à des exemples boulonnais, lillois, flamands et ardrésien du XIV ${ }^{\mathrm{e}} \mathrm{s}$. Le domaine de la cuisson est caractérisé principalement par une cuisson mijotée avec la présence de quatre oules. L'oule $\mathrm{O} 4$, à lèvre en crochet saillant, trouve des homologues à Saint-Omer et Béthune du XIII ${ }^{\mathrm{e}}$ s. De même, l'oule
O3, à lèvre élargie légèrement rentrante, peut être comparée à des exemplaires audomarois des $\mathrm{XII}^{\mathrm{e}}-\mathrm{XIII}{ }^{\mathrm{e}}$ siècle et béthunois du XIV ${ }^{\mathrm{e}} \mathrm{s}$. On peut également mentionner un poêlon de type PO2 (non dessiné, à lèvre saillante de section « en amande ») présageant une cuisson frite et deux fragments de lèchefrite, symbolisant une cuisson en rôt. Deux éléments viennent clairement abonder vers une datation tournée vers le $\mathrm{XIII}^{\mathrm{e}} \mathrm{s}$. Il s'agit du bassin B2, à lèvre confondue, éversée et bout arrondi, avec un décor de grosses digitations sur tout le pourtour du col ressemblant à un individu du XIII" ${ }^{\mathrm{e}}$ s. de la fouille béthunoise «boulevard Jean Moulin ». Le pot à goulot PG1, avec son goulot de section circulaire rattaché à la lèvre par une bande de pâte rappelle des occurrences de la seconde moitié $\mathrm{du} \mathrm{XII}^{\mathrm{e}}$ s. à Saint-Omer et des $\mathrm{XII}^{\mathrm{e}}-\mathrm{XIII}^{\mathrm{e}} \mathrm{s}$. à Oudenaarde, en Flandre occidentale. Même si de nombreux éléments se retrouvent dans des contextes $\mathrm{du} \mathrm{XIV}^{\mathrm{e}} \mathrm{s}$., certaines formes quasi « archaïques » marquent un réel balancement entre le $\mathrm{XIII}^{\mathrm{e}}$ et le $\mathrm{XIV}^{\mathrm{e}} \mathrm{s}$.

\section{Catalogue (fig. 18)}

1. $\left(\mathrm{N}^{\circ}\right.$ inv. 1041.8). Pichet PI2 : pichet à col cannelé et renflement interne. Terre cuite grise. D. $13 \mathrm{~cm}$. Alvey, Verhaeghe 1981, XIII $\mathrm{e}_{-}$ milieu XIV s. ; Barbe, Debs, Roy 1994, XIV ${ }^{\mathrm{e}}$ s.; Barbe et al. 1997, milieu XIII ${ }^{\mathrm{e}}$ s.; Blieck 1996, milieu XIII ${ }^{\mathrm{e}}$-premier quart XIV et XIV ${ }^{\mathrm{e}}$ s.; De Groote 2008, XIII ${ }^{\mathrm{e}}$-fin XIV ${ }^{\mathrm{e}}$ s.; Despriet 1998, 1250-1325; Marcy 2004, XIV ${ }^{\mathrm{e}}$ s.; Roy 1997, second tiers XIII ${ }^{\mathrm{e}}$ s.; Vincent 2010a, fin XIV ${ }^{\mathrm{e}}$-début XV $\mathrm{XV}^{\mathrm{e}}$ s.; Vincent 2010b, seconde moitié XIII ${ }^{\mathrm{e}}$ $X^{\mathrm{e}}$ s.; Vincent 2010c, XIV ${ }^{\mathrm{e}}$ s.; Vincent 2011a, XIV -début XV $\mathrm{XV}^{\mathrm{e}}$ s.; Vincent 2011b, fin XIV ${ }^{\mathrm{e}}$-début $\mathrm{XV}^{\mathrm{e}} \mathrm{s}$.

2. $\left(\mathrm{N}^{\circ}\right.$ inv. 1041.13). Pichet PI3: pichet à lèvre en bandeau. Terre cuite grise. D. $10 \mathrm{~cm}$. Debs, Marcy 2006, fin XIV -début XV ${ }^{\mathrm{e}}$ s., De Groote 2008, L61B, 1200-1300/1300-1400; Belot, Canut 1997, fin XIV -début XV $\mathrm{XV}^{\mathrm{e}}$ s.; Pouriel 2002, seconde moitié XIV s.; Marcy 2004, XIV ${ }^{\mathrm{e}} \mathrm{s}$.

3. $\left(\mathrm{N}^{\circ}\right.$ inv. 1041.18). Oule $\mathrm{O} 3$ : oule à lèvre élargie légèrement rentrante. Terre cuite grise. D. $21 \mathrm{~cm}$. Vincent (en cours) a, XII ${ }^{\mathrm{e}}$ XIII $^{\mathrm{e}} \mathrm{s}$.; Vincent (en cours) b, XIV ${ }^{\mathrm{e}} \mathrm{s}$.

4. $\left(\mathrm{N}^{\circ}\right.$ inv. 1016.2). Oule $\mathrm{O} 4$ : oule à lèvre en crochet saillant. Terre cuite grise. D. $22 \mathrm{~cm}$. Vincent (en cours) a, XIII ${ }^{\mathrm{e}} \mathrm{s}$; ; Vincent (en cours) b, XIII $\mathrm{e}$.

5. ( $\mathrm{N}^{\circ}$ inv. 1041.3). Lèchefrite L1 : lèchefrite à lèvre droite, épaisse présentant une légère concavité en partie supérieure. Terre cuite rouge glaçurée.

6. ( $\mathrm{N}^{\circ}$ inv. 1041.15). Bassin $\mathrm{B} 2$ : bassin à lèvre confondue, éversée et bout arrondi, avec un décor de grosses digitations sur tout le pourtour du col. Terre cuite grise. D. $32 \mathrm{~cm}$. Vincent (en cours) b, XIII ${ }^{\mathrm{e}} \mathrm{s}$.

7. $\left(\mathrm{N}^{\circ}\right.$ inv. 1041.13). Pot à goulot $\mathrm{PG1}$ : pot à goulot à lèvre épaisse, légèrement éversée et bout aplati, goulot de section circulaire reliée à la lèvre par une bande de pâte. Terre cuite grise. D. indéterminé. De Groote 2008, XII ${ }^{\mathrm{e}}-\mathrm{XIII}{ }^{\mathrm{e}}$ s., Vincent (en cours) a, seconde moitié $\mathrm{XII}^{\mathrm{e}} \mathrm{S}$.

8. $\left(\mathrm{N}^{\circ}\right.$ inv. 1017.4). Couvre-feu CF3 : couvre-feu à lèvre élargie et aplatie avec un ressaut au niveau de liaison col-panse. Terre cuite grise. D. $34 \mathrm{~cm}$. 


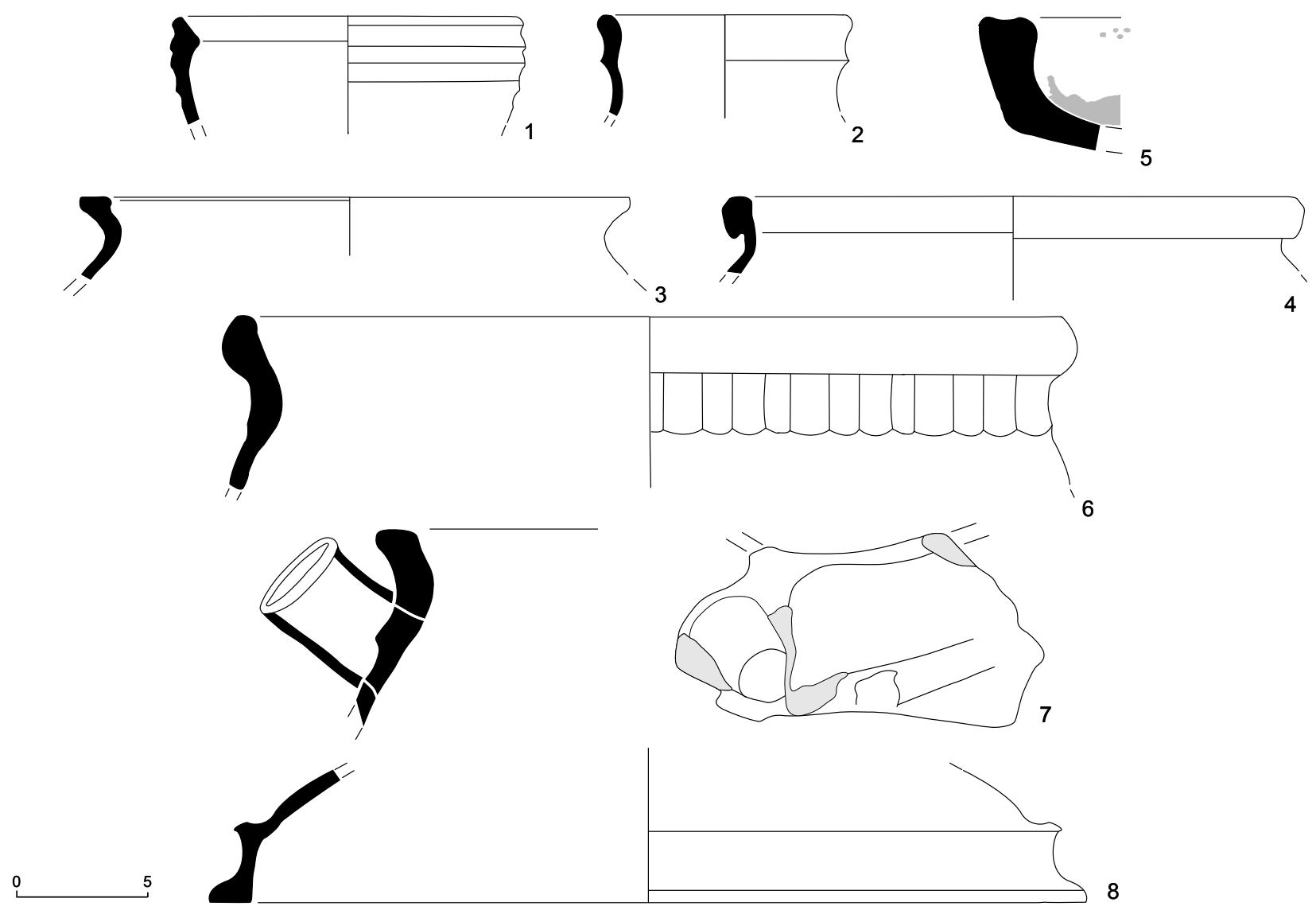

FIG. 18. - Céramiques fin XIII -début XIVe s. Éch. 1/3. Dessins et DAO V. Vincent, S. Vanholle.

La seconde phase médiévale peut également être associée à un habitat. Un fragment d'assiette A2 (non dessiné) a été découvert; celle-ci dispose d'un marli plat sans inflexion, mais toujours d'un aspect très court, caractéristique des rares assiettes découvertes en contexte du XIV ${ }^{\mathrm{e}} \mathrm{s}$. Le pichet PI2 est remplacé par le type PI1 (NMI 6), à col lisse et renflement interne qui rappelle des exemples tournaisiens de la fin du $\mathrm{XV}^{\mathrm{e}}$-début $\mathrm{XVI}^{\mathrm{e}}$ s., courtraisiens de la seconde moitié $\mathrm{du} \mathrm{XIV}^{\mathrm{e}}-\mathrm{XV}^{\mathrm{e}} \mathrm{s}$. et valenciennois de la seconde moitié $\mathrm{du} \mathrm{XV}^{\mathrm{e}} \mathrm{s}$. Trois fragments de gobelets ont également pu être observés. Ils disposent d'une panse carénée, d'une lèvre éversée, sont tous à pâte grise et peuvent trouver une comparaison du $\mathrm{XIV}^{\mathrm{e}} \mathrm{s}$. à Béthune et de la seconde moitié du $\mathrm{Xv}^{\mathrm{e}} \mathrm{s}$. à Saint-Omer. On remarque une évolution dans le domaine de la cuisson avec la disparition de l'oule et l'utilisation désormais massive des marmites, disposant le plus souvent de pieds tripodes et de deux anses opposées. Les cinq marmites déclinées en trois types différents (non dessinées) disposent toutes de références situées entre la fin du XIV ${ }^{\mathrm{e}}$ et le $\mathrm{XV}^{\mathrm{e}} \mathrm{s}$. Le poêlon $\mathrm{PO} 1$, à lèvre rabattue sur l'extérieur de section quadrangulaire avec la présence d'une légère concavité en partie supérieure peut être associé à un individu audomarois des $\mathrm{XIV}^{\mathrm{e}}-\mathrm{XV}^{\mathrm{e}} \mathrm{s}$. La céramique de préparation est ici représentée par quatre tèles (T3) et trois terrines (TR1 et TR2). Les premières, à lèvre en bandeau confondu, sont très largement répandues dans toute la région au $\mathrm{XIV}^{\mathrm{e}}$ et au

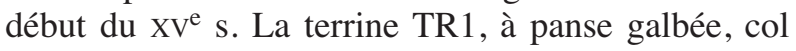
oblique et lèvre épaissie de profil subcirculaire semble également caractéristique du XIV -début $\mathrm{XV}^{\mathrm{e}} \mathrm{s}$. à Saint-Omer, Lille, Douai, Tournai et Béthune. Les couvre-feux $\mathrm{CF} 1$ et $\mathrm{CF} 2$ complètent ce panorama. Ils trouvent tous deux des références à Béthune au $\mathrm{XIV}^{\mathrm{e}} \mathrm{s}$.

Cette seconde phase, par la corrélation entre les données techniques (augmentation progressive des éléments à pâte rouge, présence de grès) et les données morphologiques, semble se situer dans la seconde moitié du XIV $\mathrm{s}$. voire tout début du $\mathrm{XV}^{\mathrm{e}} \mathrm{s}$.

\section{Catalogue (fig. 19)}

1. $\left(\mathrm{N}^{\circ}\right.$ inv. 1030.1). Pichet PI1 : pichet à col lisse avec renflement interne. Terre cuite rouge glaçurée. D. indéterminé. Challe 20072008, fin XVe-début $\mathrm{XVI}^{\mathrm{e}}$ s., Korpiun 2007, seconde moitié XIV ${ }^{\mathrm{e}}$ $\mathrm{XV}^{\mathrm{e}}$ s., Vincent 2010b, seconde moitié $\mathrm{XV}^{\mathrm{e}} \mathrm{s}$. 

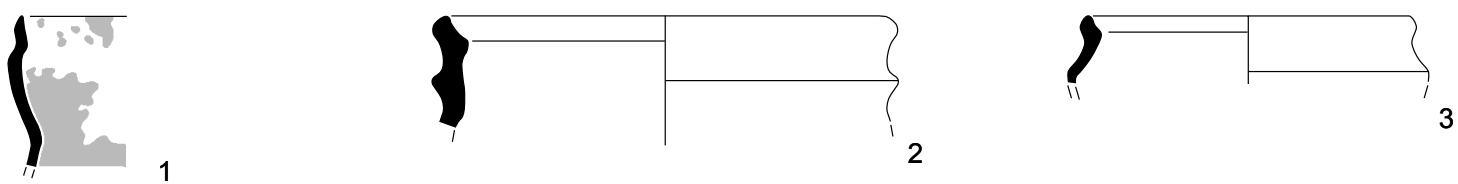

1
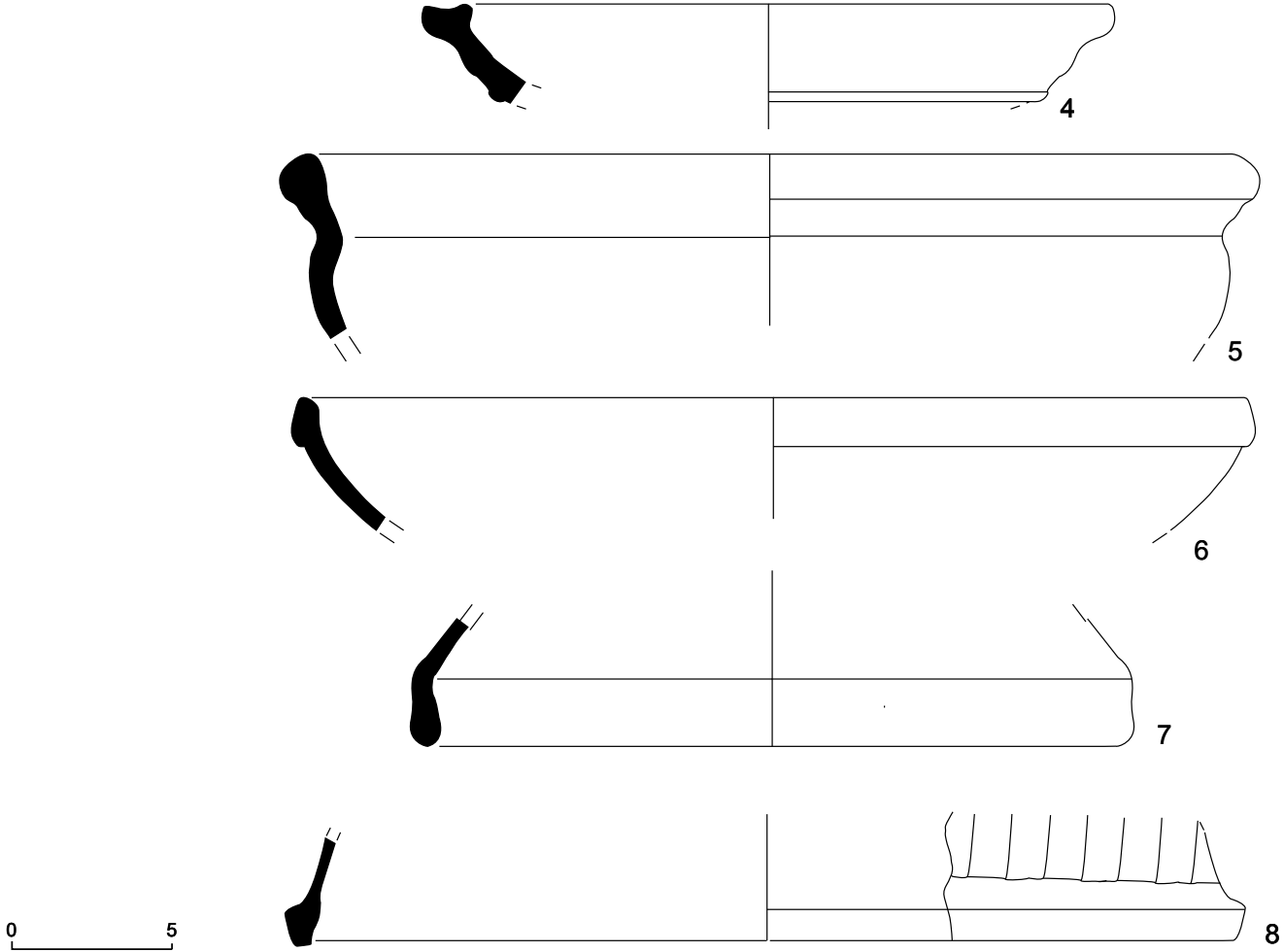

FIG. 19. - Céramiques seconde moitié XIVe-début XV $V^{e}$. Éch. 1/3. Dessins et DAO V. Vincent, S. Vanholle.

2. $\left(\mathrm{N}^{\circ}\right.$ inv. 1041.14). Cruche $\mathrm{CR} 1$ : cruche à lèvre en bandeau saillant avec inflexion interne. Terre cuite grise. D. $14 \mathrm{~cm}$

3. $\left(\mathrm{N}^{\circ}\right.$ inv. 1030.5). Gobelet $\mathrm{G} 1$ : gobelet à lèvre éversée et panse carénée. Terre cuite grise. D. $10 \mathrm{~cm}$. Roy, Barbe 1998, seconde moitié XV s.; Gubellini 2002, seconde moitié XVI ${ }^{\mathrm{e}}$ s.; Vincent (en cours) b, XIV ${ }^{\mathrm{e}} \mathrm{s}$.

4. ( $\mathrm{N}^{\circ}$ inv. 1030.9). Poêlon $\mathrm{PO} 1$ : poêlon à lèvre rabattue sur l'extérieur de section quadrangulaire avec présence d'une légère concavité en partie supérieure. Terre cuite grise. D. $22 \mathrm{~cm}$. Barbe, Roy 1994, XIV ${ }^{\mathrm{e}}-\mathrm{XV}^{\mathrm{e}}$ s.; Blieck 1996, XIV ${ }^{\mathrm{e}}$ s.; Bonvarlet 1998, $\mathrm{XIV}^{\mathrm{e}} \mathrm{s}$.; Vincent (en cours) b, XIV ${ }^{\mathrm{e}} \mathrm{s}$.

5. $\left(\mathrm{N}^{\circ}\right.$ inv. 1025.2). Terrine TR1: terrine à panse légèrement galbée, col oblique et lèvre épaissie de profil subcirculaire. Terre cuite grise. D. 31 cm. Barbe, Barret 1995, 1300-1375; Blieck 1996, XIV s.; Bonvarlet 1998, début XV' s.; Challe 2007-2008, fin XIVdébut $\mathrm{XV}^{\mathrm{e}}$ s.; Debs, Marcy 2006, XIV e s.; De Groote 2008, 13001400; Verhaeghe 1987, 1300-1375; Vincent 2011a, XIVe-début $\mathrm{XV}^{\mathrm{e}}$ s.; Vincent 2012, XIV ${ }^{\mathrm{e}}$ s.; Vincent (en cours) b, XIV $\mathrm{s}$.

6. $\left(\mathrm{N}^{\circ}\right.$ inv. 1025.10). Tèle $\mathrm{T} 1$ : tèle à lèvre en bandeau confondu. Terre cuite grise. D. $30 \mathrm{~cm}$. Alvey, Verhaeghe 1981, 1250-1350; Blieck 1996, XIV e s.; Bonvarlet 1998, fin XIV -début XVe s.; Challe, Leblois 2008, fin XIVe-début XV $\mathrm{XV}^{\mathrm{e}}$ s.; De Groote 2008, 1300-1375; Pouriel 2002, seconde moitié XIV ${ }^{\mathrm{e}}$ s.; Verhaeghe 1987, XIV s.; Vincent 2010d, seconde moitié $X^{2} V^{\mathrm{e}}$-début $\mathrm{XV}^{\mathrm{e}} \mathrm{s}$.; Vincent 2010c, fin XIV ${ }^{\mathrm{e}}$-début $\mathrm{XV}^{\mathrm{e}} \mathrm{s}$.; Vincent $2010 \mathrm{~g}$, seconde moitié XIV -début $\mathrm{XV}^{\mathrm{e}}$ s., Vincent (en cours) b, XIII' ${ }^{\mathrm{e}}-\mathrm{XIV}^{\mathrm{e}} \mathrm{s}$.

7. ( $\mathrm{N}^{\circ}$ inv. 1030.2). Couvre-feu $\mathrm{CF} 1$ : couvre-feu à lèvre droite et bout arrondi. Terre cuite grise. D. $23 \mathrm{~cm}$. Despriet 1998, 1250-
1325; Vincent 2011a, XIV -début XV $\mathrm{XV}^{\mathrm{e}}$ s.; Vincent (en cours) b, $\mathrm{XIV}^{\mathrm{e}} \mathrm{s}$.

8. ( $\mathrm{N}^{\circ}$ inv. 1000.5). Couvre-feu $\mathrm{CF} 2$ : couvre-feu à lèvre de section triangulaire, légèrement rentrante. Vincent (en cours) $b, \mathrm{XIV}^{\mathrm{e}} \mathrm{s}$.

\subsubsection{Une tessonnière du XVII ${ }^{e}$ s.?}

Cette troisième phase a été déterminée uniquement à partir du mobilier découvert dans le comblement de la tranchée de fondation 1002 de la tranchée 1 . Ont été échantillonnés 152 fragments pour cinquante-huit individus. Les tessons ont été véritablement pilés dans le but de drainer le mur supérieur. Deux éléments présentent nettement une surcuisson, peut-on aller jusqu'à envisager des ratés de cuisson de potier? Les productions rencontrées sont moins diversifiées que les deux phases précédentes (tab. 2). La terre cuite grise est minoritaire avec onze fragments soit $7,2 \%$ du corpus, le reste se compose essentiellement d'éléments à pâte rouge. Ceux-ci se déclinent majoritairement en fragments glaçurés (à 57,8 \%) et en éléments glaçurés avec en plus, l'ajout d'un engobe blanc sous la glaçure (20,3\% de TCR-gl/eng). À ceux-ci s'ajoutent deux modes de décor très particulier: le décor $a$ 


\begin{tabular}{lrr}
\hline & \multicolumn{2}{c}{ P3 } \\
\hline TCG & NR & \% NR \\
\hline TCR & 11 & $7,2 \%$ \\
\hline TCR-gl & 5 & $3,3 \%$ \\
\hline TCR-gl/eng & 88 & $57,9 \%$ \\
\hline TCR-gl/sgraf & 31 & $20,4 \%$ \\
\hline TCR-gl/corne & 5 & $3,3 \%$ \\
\hline grès & 11 & $7,2 \%$ \\
\hline total & 1 & $0,7 \%$ \\
\hline
\end{tabular}

Tableau 2. - Les catégories céramiques de la phase 3, XVII ${ }^{e}$ s. Nombre de restes et pourcentage.

sgraffiato (TCR-gl/sgraf) et le décor à la corne (TCR$\mathrm{gl} /$ corne). Le premier consiste en un décor incisé avec un jeu de couleur entre la pâte, l'engobe et la glaçure (fig. 20). Cette technique est véritablement caractéristique du XVI ${ }^{\mathrm{e}}$ s. et est encore employée au XVII ${ }^{\mathrm{e}} \mathrm{s}$. par certains ateliers (comme celui de Beauvais). Le second se compose d'un décor à la barbotine le plus souvent de couleur blanche, déposée à la corne de vache. Cette technique apparaît dès le début du XVII s. et perdure jusqu'au $\mathrm{XVIII}^{\mathrm{e}} \mathrm{s}$. Ces deux catégories représentent respectivement $3,3 \%$ et $7,2 \%$. On peut enfin mentionner une panse de grès, signe d'une importation sans doute rhénane vu la couleur de la pâte.

En plus de la grande homogénéité des pâtes, le faible éventail morphologique plaide également en faveur d'un possible rejet de production. Les cinquante-huit individus se déclinent principalement en quatre formes (fig. 21). La mieux représentée avec trente-quatre individus est la jatte $\mathrm{J} 1$ qu'on pourrait qualifier de tèle; elle se compose d'une lèvre épaissie " en amande », parfois rainurée, et on perçoit sur certains éléments la présence d'un bec verseur. D'après la typologie des tèles à lait de l'abbé Tieghem et de J. Cartier, il s'agirait d'une lèvre caractéristique du $\mathrm{XVIII}^{\mathrm{e}} \mathrm{s}$. L'écuelle E1 (quatorze individus) présente une lèvre en bandeau et des éléments de préhension

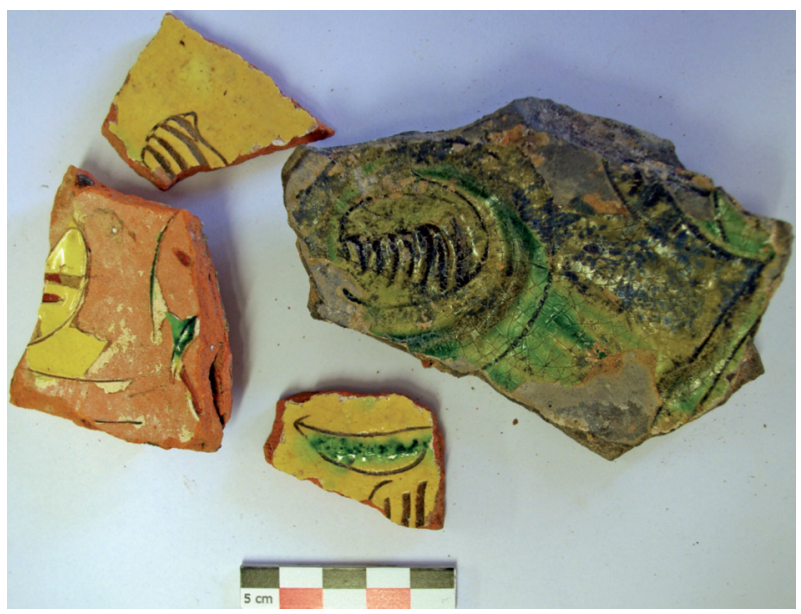

FIG. 20. - Panses de céramique décorées a sgraffiato, US 1002, XVII s. (C) V. Vincent.

horizontaux. Ce type d'écuelle apparaît à la fin du $\mathrm{XVI}^{\mathrm{e}} \mathrm{s}$. et semble caractéristique du XVII $\mathrm{s}$. Ces formes sont réservées au service de table et sont généralement en TCR-gl/eng. Sept individus sont des marmites de type M5 (non dessinées) et deux sont des pots à anse PA2, à lèvre droite légèrement arrondie. Ces dernières peuvent trouver des comparaisons au $\mathrm{XVI}^{\mathrm{e}}$ s., néanmoins la présence d'un décor à la corne les ramène clairement vers le $\mathrm{XVII}^{\mathrm{e}} \mathrm{s}$.

La corrélation de ces différents éléments à savoir la présence de TCR-gl/sgraf simultanément à de la TCR$\mathrm{gl} /$ corne, les écuelles et les jattes semblent bien déterminer le XVII ${ }^{\mathrm{e}}$ s., sans qu'il soit une nouvelle fois possible d'être plus précis, faute de références supplémentaires. Les études céramiques des contextes modernes font encore cruellement défaut à la discipline.

\section{Catalogue (fig. 21)}

1. ( $\mathrm{N}^{\circ}$ inv. 1002.12). Écuelle $\mathrm{E} 2$ : écuelle à lèvre en bandeau et éléments de préhension horizontaux. Terre cuite rouge glaçurée sur engobe. Marcy 2004, début XVII ${ }^{\mathrm{e}}$ s.; Belot, Canut 1997, XVII ${ }^{\mathrm{e}}$ s.; Vincent 2012, milieu XVI ${ }^{\mathrm{e}}$ s.; Vincent 2011a, seconde moitié XVI ${ }^{\mathrm{e}}$ début XVII ${ }^{\mathrm{e}} \mathrm{s}$.

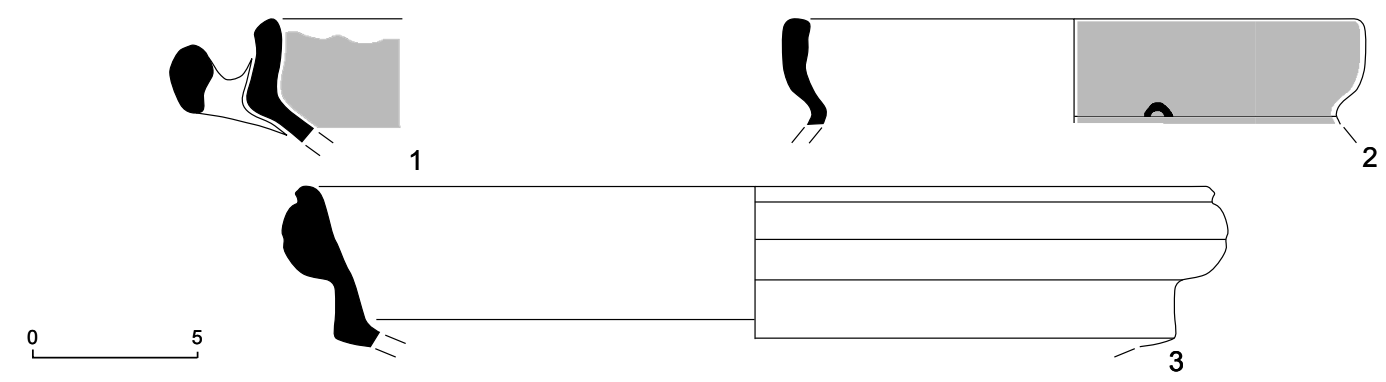

FIG. 21. - Céramiques du XVII $s$. Éch. 1/3. Dessins et DAO V. Vincent. 


\begin{tabular}{lrr}
\hline & \multicolumn{2}{c}{ P4 } \\
\hline TCG & NR & \% NR \\
\hline TCR-gl & 6 & $22,2 \%$ \\
\hline TCR-gl/eng & 12 & $44,4 \%$ \\
\hline TCR-gl/corne & 2 & $7,4 \%$ \\
\hline TCB-gl & 1 & $3,7 \%$ \\
\hline TCB-gl-brune & 3 & $11,1 \%$ \\
\hline grès & 1 & $3,7 \%$ \\
\hline faïence & 1 & $3,7 \%$ \\
\hline total & 1 & $3,7 \%$ \\
\hline & 27 & $99,9 \%$ \\
\hline
\end{tabular}

Tableau 3. - Les catégories céramiques de la phase 4, XVIII ${ }^{e}$. Nombre de restes et pourcentage.

2. $\left(\mathrm{N}^{\circ}\right.$ inv. 1002.21). Pot à anse PA2: pot à lèvre droite légèrement arrondie. Terre cuite rouge glaçurée avec décor à la corne. D. $18 \mathrm{~cm}$

3. ( $\mathrm{N}^{\circ}$ inv. 1002.23). Jarre $\mathrm{J} 1$ : jatte à lèvre épaissie de section « en amande ». Terre cuite rouge. D. $28 \mathrm{~cm}$. Tieghem, Cartier 1976, $\mathrm{XVIII}{ }^{\mathrm{e}} \mathrm{s}$.

\subsubsection{La fosse des statues (US 1010 et 1011)}

La fosse 1010, dans laquelle ont été entreposées les statues, a livré dans son comblement (1011) un très petit nombre de céramiques (vingt-sept fragments et cinq individus). Il convenait, vue l'importance de la découverte, d'en faire une étude à part. Nous mettrons le doigt une fois de plus sur le manque de publications sur la céramique moderne. Les ouvrages sur la faïence et la porcelaine sont nombreux, mais la céramique commune est totalement passée sous silence.

Les productions céramiques sont ici très variées (tab. 3): grès, faïence, terre cuite blanche glaçurée et un autre avec une glaçure brune. La terre cuite grise est encore présente avec six panses. Les pâtes rouges se déclinent en terre cuite rouge glaçurée $(44,4 \%)$, terre cuite rouge glaçurée sur engobe $(7,4 \%)$ et lèvre décorée à la corne $(3,7 \%)$. Le fond en faïence est extrêmement fin. Le décor se compose de pétales de fleurs bleues sur une partie et d'un double arc de cercle sur l'autre partie. Il doit s'agir d'une forme globalement plate de type sous-tasse. Ce fragment rappelle le décor des assiettes découvertes dans l'ancien couvent des Capucins à Douai ${ }^{17}$, ou ceux des faïences de Tourcoing ${ }^{18}$, le tout daté du XVIII ${ }^{\mathrm{e}} \mathrm{s}$. L'assiette A1, dont le marli est décoré avec de très fines stries à la corne reste également tout à fait courante au XVIII $\mathrm{s}$. Une panse présente une face interne couverte de gla-

17. - BARBIEUX 1978, p. 31.

18. - BARBIEUX 1989, p. 211-212.

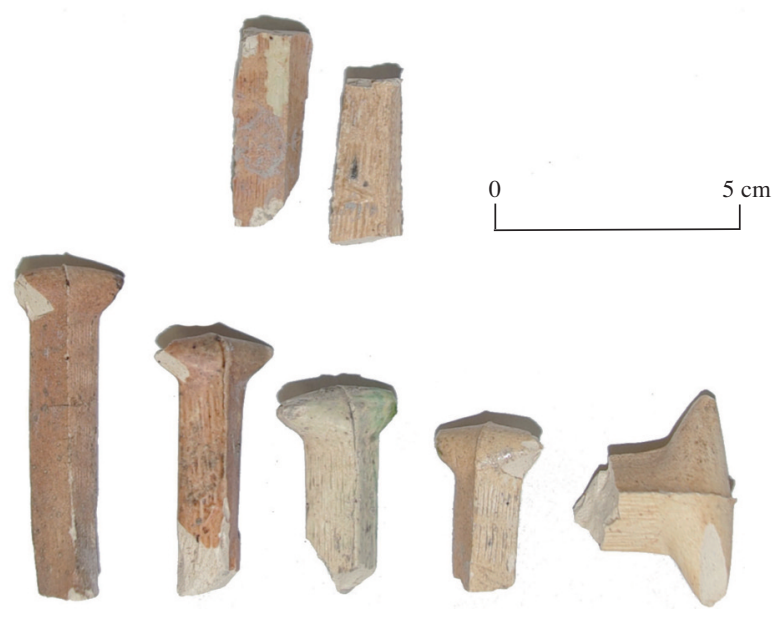

FIG. 22. - Fragments de pernettes, US 1015, XIX ${ }^{e}$ s. (C) V. Vincent.

çure stannifère et une face externe enduite d'une glaçure marron très prononcée. Ce type de production dite «cul noir » est réservé aux éléments de cuisson et apparaît à partir de 1730 dans plusieurs manufactures ${ }^{19}$. La lèvre du poêlon PO4 (non dessiné) en quart de cercle affiné est assez courante sur les pots de chambre et pots à cuire du XVIII $\mathrm{e}$ s

\subsubsection{La tessonnière du XIX ${ }^{e} s$.}

La tessonnière se situe en tranchée 3, structure 1015. Les tessons étaient extrêmement fragmentés, pilés et agglomérés avec une épaisse couche d'argile, parfois même avec un peu de mortier blanc. Un premier échantillonnage a été effectué du terrain à la post-fouille. Au vu de la quantité de panses centimétriques et de la confirmation d'un rejet d'atelier, un second tri a été décidé. Pour rester dans les limites du diagnostic, seules les lèvres, certains fonds et éléments de préhension ont été conservés pouvant au mieux refléter la production orchésienne. Les indices de production sont nombreux. Ont été identifiés des fragments de pernettes (fig. 22) qui étaient insérées dans les cazettes pour maintenir les objets séparés les uns des autres dans le four, et des ratés de cuisson notamment au niveau de la glaçure.

La production se compose majoritairement d'éléments à pâte blanche d'aspect friable. Les glaçures se partagent entre le jaune laiteux, le vert et le brun-noir. On trouve également des éléments à pâte rouge glaçu-

19. - MeUNIER et al. 2012, p. 56. 

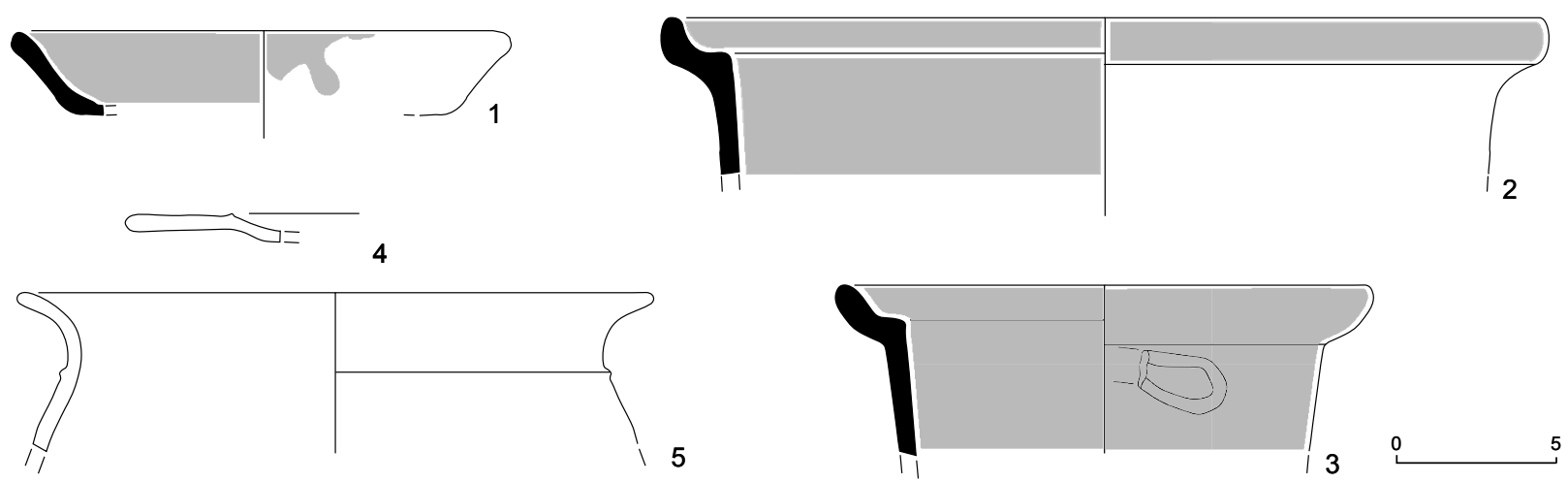

FIG. 24. - Céramiques du XIX $s$.

Dessins et DAO V. Vincent.

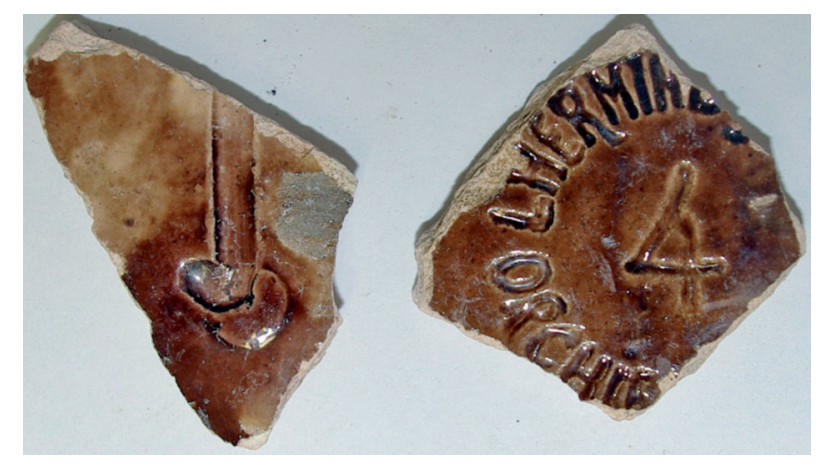

FIG. 23. - Marque de manufacture, US 1015, XIXe s. (c) V. Vincent.

rée, proportionnellement en quantité moindre. Une marque sur un fond d'objet nous permet clairement d'identifier cette production: LHERMIN...4... ORCHIE... (fig. 23). Il s'agit de la production de deux frères L'Herminé, créée en 1886 à Orchies. Elle fusionne en 1923 avec l'usine d'Hamage pour former la fabrique renommée de "Moulin des Loups et Hamage ». La fabrique de L'Herminé est principalement connue pour ses productions de faïence et carafes humoristiques en forme d'animaux. Cette production est donc bien balisée dans le temps et se limite au dernier quart du $\mathrm{XIX}^{\mathrm{e}} \mathrm{s}$. Le répertoire morphologique est assez limité (fig. 24). Il se compose d'une fabrication de petites coupes (CPE1) à fond plat et lèvre éversée, majoritairement à glaçure jaune (cent cinquante-neuf individus), pouvant également être recouvert d'une glaçure verte (trente-deux individus). Les tèles sont également bien représentées (trentesept individus en tout - non dessinées). Elles disposent d'une lèvre épaisse et arrondie pouvant parfois être rainurée, avec une liaison panse/fond marquée par une saillance externe. Ces tèles sont uniquement en pâte rouge glaçurées. La dernière forme caractéristique est le pot à lèvre en quart de cercle (PLQC1 et 2 ), pour lequel on trouve deux modules: un petit dont le diamètre tourne autour des $15 \mathrm{~cm}$, et un grand avec un diamètre de $30 \mathrm{~cm}$. Certains fragments indiquent la présence d'éléments de préhension horizontaux, qui peuvent les apparenter à des pots de fleurs. Ceux-ci peuvent être en pâte rouge à glaçure orange, en pâte blanche à glaçure verte (TCB-gl-V) ou plus majoritairement à pâte blanche avec une glaçure jaune à l'intérieur et une glaçure brun foncé à l'extérieur (TCB-glJ/B). Dans une quantité moindre, des éléments de faïence ont également été recensés. Ils proviennent peut-être davantage de rejets de consommation plus que de production. Ils se composent principalement d'assiettes à marli plat et fin et de pots à lèvre éversée, identifiés comme des pots de chambre.

\section{Catalogue (fig. 24)}

1. $\left(\mathrm{N}^{\circ}\right.$ inv. 1015). Coupe $\mathrm{CPE} 1$ : coupelle à lèvre mince et éversée. Terre cuite blanche à glaçure jaune. D. $16 \mathrm{~cm}$

2. ( $\mathrm{N}^{\circ}$ inv. 1015). PLQC1 : pot à lèvre en quart de cercle de grand module. Terre cuite blanche à glaçure verte. D. $28 \mathrm{~cm}$

3. $\left(\mathrm{N}^{\circ}\right.$ inv. 1015). PLQC2: pot à lèvre en quart de cercle de petit module. Terre cuite blanche à glaçure jaune à l'intérieur et brune à l'extérieur. D. $17 \mathrm{~cm}$

4. $\left(\mathrm{N}^{\circ}\right.$ inv. 1015.2). Assiette $\mathrm{A} 3$ : assiette à marli plat et fin. Faïence. D. indét.

5. ( $\mathrm{N}^{\circ}$ inv. 1015.8). Pot de chambre: pot à lèvre éversée avec une légère inflexion au niveau de la liaison panse/lèvre. Faïence. D. $20 \mathrm{~cm}$

\subsection{Conclusion}

L'étude de la céramique du diagnostic d'Orchies « Rue Letellier» montre une occupation s'échelonnant entre la fin du XIII ${ }^{\mathrm{e}}$ et le dernier quart du XIX ${ }^{\mathrm{e}} \mathrm{s}$. Les deux assemblages médiévaux montrent un spectre 
céramique découvert habituellement en contexte d'habitat, avec de la céramique de table, de cuisson, de préparation et de vie quotidienne. L'approvisionnement semble régional. Des productions des régions douaisiennes, valenciennoises et tournaisiennes semblent attestées. La phase du XVII ${ }^{\mathrm{e}} \mathrm{s}$. est davantage marquée par un rejet possible de production. Deux éléments présentent des traces de surcuisson, les pâtes sont homogènes et le panel morphologique restreint à quatre formes. Le matériel issu du comblement de la fosse des statues est tout à fait indigent, mais semble converger vers une datation située dans la seconde moitié du XVIII ${ }^{\mathrm{e}} \mathrm{s}$. (faïence finement décorée et faïence à «cul noir »). Enfin, la dernière phase, datée du dernier quart du $\mathrm{XIX}^{\mathrm{e}} \mathrm{s}$., marque un nouveau rejet de production orchésienne sous forme d'une tessonnière.

\section{DE LA FOUILLE AU MUSÉE : CONSERVATION ET VALORISATION (M. Audoly)}

La restitution de ce patrimoine archéologique à tous est aujourd'hui permise grâce au généreux don de M. Frédéric Rault, gérant de la Société Macimmo, propriétaire du terrain où ont été mises au jour les quatre statues. La législation (Livre $\mathrm{V}$ du Code du Patrimoine) prévoit en effet que les objets mis au jour lors d'opérations d'archéologie préventive appartiennent pour partie au propriétaire du terrain où ils ont été découverts et pour partie à l'État, à valeur égale. En février 2015, M. Frédéric Rault a renoncé à exercer son droit de propriété sur la moitié des découvertes réalisées, dont les statues, pour en faire don à l'État.

Étant donné l'intérêt archéologique et la qualité artistique de cet ensemble, la DRAC Nord-Pas-deCalais - Service régional de l'Archéologie, qui a pour mission la conservation, la connaissance et la valorisation du patrimoine archéologique, a souhaité déposer les quatre statues d'Orchies au Palais des BeauxArts de Lille. La Ville de Lille a apporté tout son soutien à cette démarche en acceptant le dépôt de l'État en conseil municipal, le 2 juillet 2015, et en prenant en charge la restauration des statues. Cet intérêt, témoigné par la Ville de Lille et le Palais des BeauxArts à la découverte d'Orchies, se concrétisera par la présentation de l'ensemble des statues à l'issue de leur restauration, puis par l'intégration des statues de sainte Agnès et de sainte Marie-Madeleine au parcours permanent des collections, dans la galerie dédiée à l'art des Anciens Pays-Bas.

Ainsi, grâce à la générosité et au sens civique de M. Frédéric Rault, gérant de la société Macimmo, ce patrimoine archéologique rare est mis en valeur et rendu accessible à tous, mettant par là-même en lumière le travail des archéologues et l'exceptionnelle mobilisation et collaboration de plusieurs partenaires institutionnels, du terrain jusqu'au musée, sous la coordination de la DRAC - Service régional de l'Archéologie.

Mots-clés: Moyen Âge, moderne, contemporain, Nord, Orchies, fortifications, habitat, sculpture, statues, céramique, production, sainte Agnès, sainte Marie-Madeleine, moines, Brabant, Hainaut.

\section{Bibliographie}

Alvey, Verhaeghe 1981 : Alvey R. C., Verhaeghe F., «Medieval pottery from Wissant (N. France) », Medieval ceramics, 5, 1981, p. 35-43.

Arcelin, Tuffreau-Libre 1998 : Arcelin P., TufreauLIBRE M., La quantification des céramiques : conditions et protocole. Actes de la table ronde du Centre archéologique européen du Mont-Beuvray, Glux-en-Glenne, 7-9 avril 1998, Glux-en-Glenne, 1998. 139 p. (Collection Bibracte, 2)

Barbe, Debs, Roy 1994 : Barbe H., Debs L., Roy E., "Développements récents de l'archéologie urbaine à Lens (1992-1994) », Gauheria, 1, 1994, p. 5-22.

Barbe, Roy 1994 : Barbe H., Roy E., Saint-Omer, rue Allent. Construction de 31 garages, 1994. (Document final de synthèse inédit, SRA Nord-Pas-de-Calais, Lille)

Barbe, Baret 1995 : Barbe H., Barret M., Saint Omer "Ancienne maison d'arrêt» rue Taviel, 1995. (Document final de synthèse inédit, SRA Nord-Pas-de-Calais, Lille)

Barbe et al. 1997 : Barbe H., Deschodt L., Routier J.-C., Roy E., Le site du quai des Salines à Saint-Omer. De l'aménagement d'un réseau hydrographique à l'urbanisation industrielle d'une ville médiévale, 1997. (Document final de synthèse inédit, SRA Nord-Pas-de-Calais, Lille)

BARBET 2009 : BARBET C., Orchies (Nord), ZAC de la Carrière dorée, tranche 2, Douai, 2009,116 p. (Rapport de diagnostic. Communauté d'agglomération du Douaisis)

BARbieUX 1978 : BarbieuX J., « La fontaine Saint-Maurand. Céramiques post-médiévales », Les Amis de Douai, 7 (6), 1978, p. 27-33.

Barbieux 1989 : Barbieux J., « Céramiques de l'époque Révolutionnaire à Tourcoing (Nord) », dans La céramique médiévale et post-médiévale dans le Nord de la France. Actes du colloque de Lille (26-27 mars 1988), s.1., 1989, p. 209-213. (Nord-Ouest archéologie, hors série)

Barbieux, Guillouet 1979 : Barbieux J., Guillouet J., «Céramiques du XVIII" siècle à Douai (Nord)», Septentrion, 9, 1979, p. 1-14.

Belot, Canut 1997 : Belot E., Canut V., Le cru et le cuit. Dieux oubliés et pots cassés du Boulonnais. Les dieux de Boulogne durant l'Antiquité gallo-romaine. Vestiges de l'équipement céramique de cuisine et de table du Moyen Âge à l'époque moderne. Éléments d'archéologie boulonnaise, 5, Boulogne-sur-Mer, 1997, 180 p., ill. 
BLIECK 1996 : BLIECK G., « Céramiques et objets divers du $\mathrm{XIV}^{\mathrm{e}}$ siècle mis au jour dans une latrine du château dit de Courtrai à Lille », dans La céramique très décorée dans l'Europe du Nord-Ouest ( $X^{e}-X V^{e}$ siècle). Actes du colloque de Douai (7-8 avril 1995), Berck-sur-Mer, 1996, p. 183-232. (Nord-Ouest Archéologie, 7)

Bonvarlet 1998 : Bonvarlet A., Un habitat médiéval rue Mongat à Douai (XIII $-X V^{e}$ siècle), Douai, 1998, 203 p. (Archaeologia Duacensis, 12)

Challe 2007-2008: Challe S., «Céramique médiévale aux Douze Césars à Tournai », Vie archéologique, 66-67, 20072008, p. 87-114.

Challe, Leblois 2008 : Challe S., Leblois E., « Étude et interprétation de la céramique médiévale et du matériel métallique mis au jour à Saint-Ghislain sous le foyer SainteElisabeth », Annales du cercle d'histoire et d'archéologie de Saint-Ghislain et de la région, 9, 2008, p. 60-97.

Debs 2013 : Debs L., Orchies, rue Lettelier, 2013, 68 p. (Rapport de diagnostic, Service régional de l'archéologie, Nord-Pas-de-Calais)

Debs, Marcy 2006 : Debs L., Marcy T., " L'étude céramique », dans DeBs L., Lille, Rue des Tanneurs, volume 2, oct.déc. 2000, avril-septembre 2001, 2006. (Document final de synthèse inédit, SRA Nord-Pas-de-Calais)

De Groote 2008 : De Groote K., Middeleeuws aardewerk in Vlaanderen. Techniek, typologie, chronologie en evolutie van het gebruiksgoed in de region Oudenaarde in de volle en late middeleeuwen (10de-16de eeuw) Deel I, Bruxelles, 2008, $479 \mathrm{p}$.

DESPRIET 1998 : DESPRIET P., Kortrijks aardewerk 1250-1325, Courtrai, 1998. 94 p. (Archeologische en Historische Monografieën van Zuid-West Vlaanderen, 39)

DeVenter 1545: Deventer J. VAn, Atlas des villes des Pays Bas, partie II, 1545. (Biblioteca Nacional de Espana Res/207) Draux 1980 : Draux E., Nouvelle histoire d'Orchies, Lille, $1980,533 \mathrm{p}$.

Duprat 2007 : Duprat C., Orchies (59), Rue des Acacias, 2007, 15 p. (Rapport de diagnostic inédit, SRA Nord-Pas-deCalais)

Duvosquel 1985 : Duvosquel J.-M., (dir.), Albums de Croÿ. Tome XII : châtellenies de Lille-Douai-Orchies 1, Bruxelles, 1985,232 p.

GeOfFroy 2008 : Geoffroy J.-F., Orchies (59), CD 50, 2008, 14 p. (Rapport de diagnostic inédit, SRA Nord-Pasde-Calais)

Gubellini 2002 : Gubellini L., "Céramique et verrerie en milieu hospitalier au XVI ${ }^{\mathrm{e}}$ siècle: 1'hospice Gantois à Lille », Revue du Nord-Archéologie, 84 (348), 2002, p. 145-169.

Guillot De Suduiraut 2001 : Guillot De Suduiraut S., Sculptures brabançonnes du musée du Louvre. Bruxelles, Malines, Anvers, $X V^{e}-X v I^{e}$ siècles, Paris, 2001.

Henton 2003 : Henton A., Saint-Amand-les-Eaux, Nord, «RD $169 », 2003$. (Document final de synthèse inédit, SRA Nord-Pas-de-Calais)

Hosdez 2003 : Hosdez C., Orchies (59), rue Jules Ferry, 2003, 8 p. (Rapport de diagnostic inédit, SRA Nord-Pas-deCalais)

Hosdez 2012 : Hosdez C., Orchies, Nord, 7 bis rue Louis Wattrelot, construction de garages, 2012, 9 p. (Rapport de diagnostic inédit, SRA Nord-Pas-de-Calais)

KoRPIUn 2007 : Korpiun P., Vaisselle et objets médiévaux en terre cuite à Valenciennes, Valenciennes, 2007, 150 p. Laloux 2013A: Laloux F., Orchies, Le Carnoy, tranche 4, rue des Jonquilles et rue des Bleuets, 2013, 59 p. (Rapport de diagnostic inédit, SRA Nord-Pas-de-Calais)

Laloux 2013B: Laloux F., Orchies, Le Carnoy, tranche 5, Douai, 2013, 135 p. (Rapport de diagnostic inédit, SRA NordPas-de-Calais)

Lantoine 2011 : Lantoine J., Sepmeries, Nord, Rue des Berceaux. Une occupation médiévale en périphérie de la motte castrale de Sepmeries, 2011. (Document final de synthèse inédit, SRA Nord-Pas-de-Calais)

Le CAMP 1639: Le CAMP A., Pia carmina et miscellanea quaedam, cum emblematibus, 1639, BM Lille Ms 398091 0271 .

Lhомме 1943 : Lhomme G., Petite histoire d'Orchies: suivi de quelques notes sur la commune du Canton, Lille, 1943, $101 \mathrm{p}$.

Lhomme, Carneau 1938 : Lhomme G., Carneau P., Histoire d'Orchies. I. Histoire politique et militaire (de l'origine à 1914), Lille, 1938.

LOCRE 1616: Locre Ferry De, Ferreoli Locrii Paulinatis chronicon Belgicum ab anno CCLVIII ad annum usque M.D.C. continuo perductum, tomi tres, Atrebati, 1616.

LouIs 1996 : LouIs E., «La céramique très décorée à Douai. L'état de la question ", dans La céramique très décorée dans l'Europe du Nord-Ouest ( $X^{e}-X V^{e}$ siècles). Actes du colloque de Douai d'avril 1995, Berck-sur-Mer, 1996, p. 105-120. (NordOuest Archéologie, 7)

MANIEZ 2006 : MANIEZ J., Orchies (Nord), Z.A.C. de la Carrière dorée, Douai, 2006, 52 p. (Rapport de diagnostic inédit, SRA, Nord-Pas-de-Calais)

MANiEz 2007 : Maniez J., Orchies, Z.A.C. de la Carrière Dorée, 2007, Douai, 251 p. (Rapport de fouilles inédit, SRA Nord-Pas-de-Calais)

Marcy 2004 : Marcy T., «Étude de la céramique lilloise issue de l'îlot des Tanneurs ( $3^{\mathrm{e}}$ phase de fouille: 2002$)$ ), dans CERCY C., Lille (59) «Rue des Tanneurs - Les Tanneurs 3 », mai 2002-avril 2003, Volume III - contributions. Chapitre 3: le mobilier, 2004. (Document final de synthèse inédit, SRA Nord-Pas-de-Calais)

Meunier et al. 2012 : Meunier K., Peake R., SÉGuier J.-M., Lefèvre A., RAVOIRE F., Stage d'initiation à l'étude de la céramique en Île-de-France du Néolithique aux Temps modernes: support de stage, Pantin, 2012.

Pouriel 2002 : Pouriel R., Le site de la maison de retraite à Ardres : étude de la céramique provenant d'une fosse dépotoir d'un atelier de potier, Villeneuve-d'Ascq, 2002, 154 p. (Mémoire de maîtrise inédit, Université de Lille 3)

Roger et alii 1959 : Roger F., Lhomme G., CAMEAu P., Draux E., Orchies des origines à nos jours: la Pévèle préhistorique, gallo-romaine et franque. Préambule à l'histoire d'une ville, Lille, 1959, 129 p.

Roumégoux 1992 : RoumÉGoux Y., Fiche EA 152865, 1992. (Fichier communal, Service régional de l'archéologie, NordPas-de-Calais)

Roy, Barbe 1998 : Roy E., Barbe H., « Évolution typologique et rôle domestique des céramiques de Saint-Omer du $\mathrm{XIII}^{\mathrm{e}}$ au XVIII ${ }^{\mathrm{e}}$ siècle », Revue du Nord-Archéologie, 80 (328), 1998, p. 69-97.

SÉVERIN 2008 : SÉVERIN C., Orchies, rue de la Poterne, Le Carnoy, 2008, 27 p. (Rapport de diagnostic, SRA Nord-Pas-deCalais)

STEYAerT 1994 : SteyAert J. W., Laat-gotische beelouwkunst in de Bourgondische Nederlanden, Gand, 1994, p. 120-123.

Tieghem, Cartier 1976 : Tieghem G., Cartier B., « Évolu- 
tion de la tèle à lait du $\mathrm{XIV}^{\mathrm{e}}$ au XIX $\mathrm{XI}^{\mathrm{e}}$ siècle au manoir de Quiquempois (Villeneuve-d'Ascq) », Revue du Nord, 58 (228), 1976, p. 113-136.

VERHAEGHE 1987 : VeRHAEGHE F., « La céramique en Flandre $\left(\mathrm{XIII}{ }^{\mathrm{e}}-\mathrm{XV}^{\mathrm{e}}\right.$ siècle) : quelques aspects de l'évolution et de la concurrence », dans La céramique ( $V^{e}-X I X^{e}$ siècles) fabrication, commercialisation, utilisation. Actes du premier Congrès international d'Archéologie médiévale (Paris, 4-6 octobre 1985), Caen, 1987, p. 203-225.

VERHAEGHE 1989 : VeRHAEGHE F., « La céramique très décorée du bas Moyen Âge», dans Travaux du groupe de recherches et d'études sur la céramique dans le Nord-Pas-deCalais, 1989, p. 19-113. (Nord-Ouest Archéologie, hors série) VINCENT 2010a: VinCENT V., "Étude céramique », dans Henton A., Trith-Saint-Léger, Nord, "Îlot des Fontaines ». Traces d'occupation médiévale et approche morphologique en bordure de l'Escaut, 2010 p. 11-19. (Document final de synthèse inédit, SRA Nord-Pas-de-Calais)

VinCENT 2010b: VinCENT V., «Étude céramique », dans Cercy C., Vincent V., Cambrai, Nord, 99-103 Bd Faidherbe, 2010, p. 36-47. (Document final de synthèse inédit, SRA NordPas-de-Calais)

VinCENT 2010c: VinCENT V., «Étude du mobilier céramique », dans Henton A., Raismes (59) «Rue de l'abbaye ». Diagnostic au cour de l'abbaye de Vicoigne, 2010, p. 27-30. (Document final de synthèse inédit, SRA Nord-Pas-de-Calais)

Vincent 2010d: VinCENT V., « Étude de la céramique médiévale », dans Desoutter S., Ardres, Pas-de-Calais, avenue de Calais, 2010, p. 16-19. (Document final de synthèse inédit, SRA Nord-Pas-de-Calais)
VinCENT 2010g: VinCENT V., « Étude préliminaire de la céramique d'Hondschoote », dans FAUPIN G., Hondschoote, Nord, Rue Waesendaele et Rue Coppens. Une occupation $d u X V^{e}$ $X_{V I}^{e}$ s.: Habitat et artisanat de potier, 2010, p. 100-124. (Document final de synthèse inédit, SRA Nord-Pas-de-Calais) VINCENT 2011a: VinCENT V., «Étude du mobilier», dans DeBS L., Lille, rue de Jemmapes, 2011, p. 45-65. (Document final de synthèse inédit, SRA Nord-Pas-de-Calais, Lille)

VinCENT 2011b: VinCENT V., «Étude céramique », dans LANCON M., Dunkerque, cour de ville tranche 1, 2011, p. 145184. (Document final de dynthèse inédit, SRA Nord-Pas-deCalais)

VinCent 2012 : VinCENT V., « Étude céramique médiévale en contexte défensif : la fouille de la rue du palais Rihour à Lille », dans CERCY C., Lille, rue du Palais Rihour 2008, 2012, p. 1577. (Document final de synthèse inédit, SRA Nord-Pas-deCalais, Lille)

VinCENT 2015 : Vincent V., Orchies, rue Delommez, projet de construction de logements, 2015, 35 p. (Rapport de diagnostic inédit, SRA Nord-Pas-de-Calais)

VinCENT (en cours) a: VinCENT V., «Étude céramique », dans CERCY C., Saint-Omer, Rue du Saint-Sépulcre, en cours. (Document final de synthèse inédit, SRA Nord-Pas-de-Calais, Lille)

VINCENT (en cours) b : VinCENT V., «Étude céramique », dans LANCON M., Béthune, boulevard Jean Moulin, en cours. (Document final de synthèse inédit, SRA Nord-Pas-de-Calais, Lille) 